Aus der Abteilung Pathologie

(Prof. Dr. med. H.-J. Radzun)

im Zentrum Pathologie

der Medizinischen Fakultät der Universität Göttingen

\title{
Immunhistochemischer Algorithmus zur Diagnostik maligner Keimzelltumoren des Hodens
}

\author{
INAUGURAL-DISSERTATION \\ zur Erlangung des Doktorgrades \\ der Medizinischen Fakultät \\ der Georg-August-Universität zu Göttingen
}

vorgelegt von

Katharina Mayer-Eichberger

aus

Tübingen

Göttingen 2010 
Dekan:

1. Berichterstatter:

2. Berichterstatter:

3. Berichterstatterin:
Prof. Dr. med. C. Frömmel

Priv.-Doz. Dr. med. S. Schweyer

Prof. Dr. rer. nat. J. Wilting

Prof. Dr. rer. nat. P. Virsik-Köpp

Tag der mündlichen Prüfung: 28. März 2011 


\section{Inhaltsverzeichnis}

\section{Abkürzungsverzeichnis}

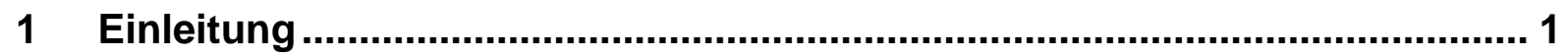

1.1 Maligne Keimzelltumoren des Hodens ................................................. 1

1.2 Immunhistochemische Diagnostik maligner Keimzelltumoren des Hodens.. 3

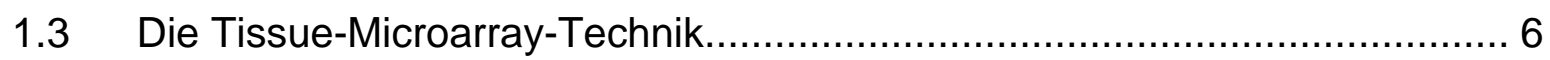

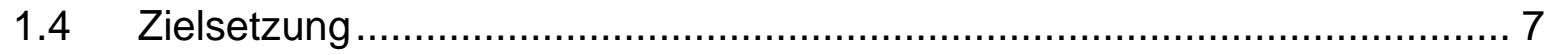

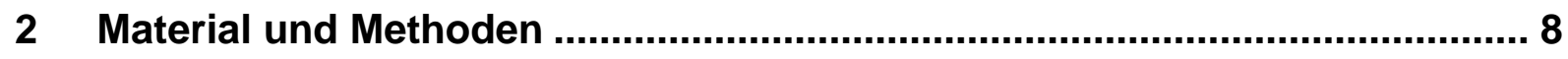

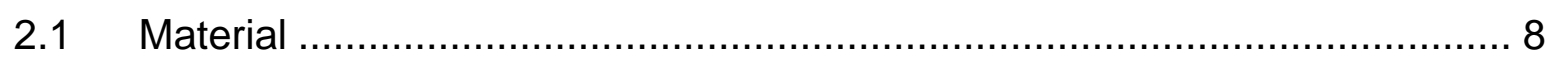

2.1.1 Verwendete Geräte ................................................................ 8

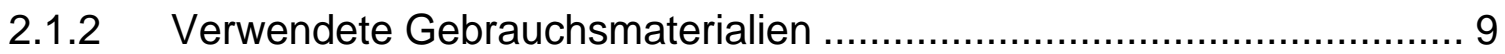

2.1.3 Verwendete Molekularbiologische Agenzien ............................... 9

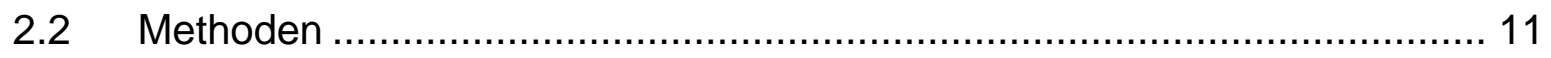

2.2.1 Zusammenstellung des Patientenkollektivs ................................. 11

2.2.2 Herstellung der Tissue-Microarrays ( TMAs ) ................................ 11

2.2.3 Herstellung von Paraffinschnitten ............................................. 14

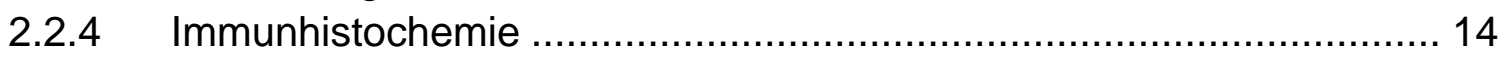

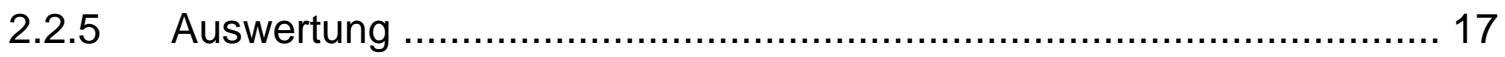

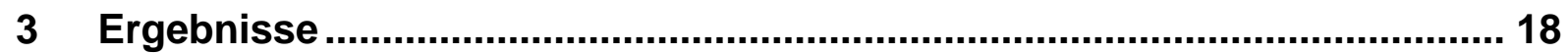

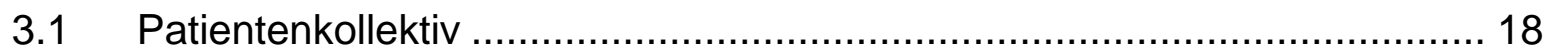

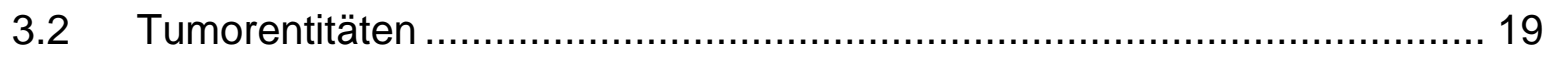

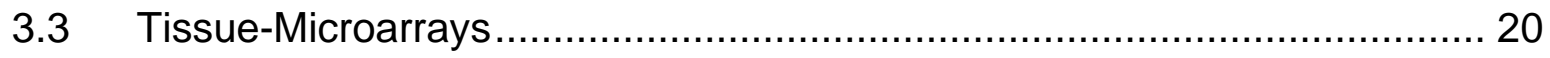

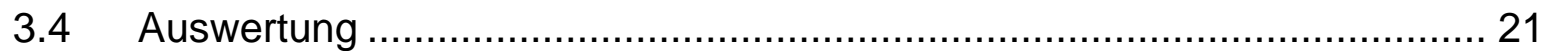

3.4.1 Expression von Pan-CK in malignen Keimzelltumoren des Hodens.... 21

3.4.2 Expression von PLAP in malignen Keimzelltumoren des Hodens....... 23

3.4.3 Expression von CD 30 in malignen Keimzelltumoren des Hodens ...... 24

3.4.4 Expression von AFP in malignen Keimzelltumoren des Hodens ......... 25

3.4.5 Expression von ß-HCG in malignen Keimzelltumoren des Hodens..... 26

3.4.6 Expression von Oct-3/4 in malignen Keimzelltumoren des Hodens .... 27

3.4.7 Expression von Sox2 in malignen Keimzelltumoren des Hodens ........ 28

3.4.8 Expression von CD 117 in malignen Keimzelltumoren des Hodens .... 29

3.4.9 Expression von D2-40 in malignen Keimzelltumoren des Hodens ...... 30

3.4.10 Expression von CD 9 in malignen Keimzelltumoren des Hodens ........ 31

3.5 Tabellarische Übersicht der Ergebnisse .......................................... 32

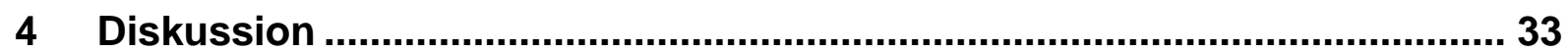

4.1 Patientenkollektiv und histopathologische Einteilung .......................... 33 
4.2 Immunhistochemisches Expressionsprofil von TGCT …..................... 34

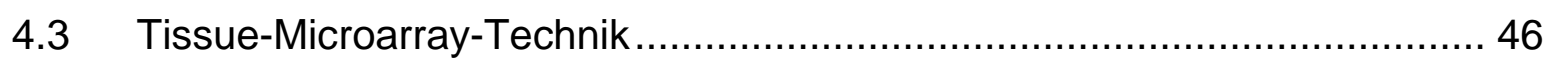

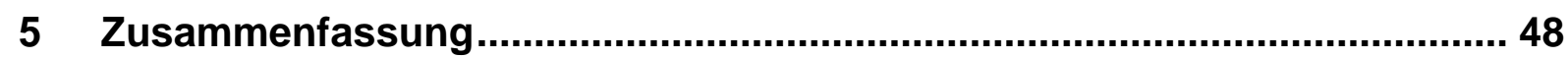

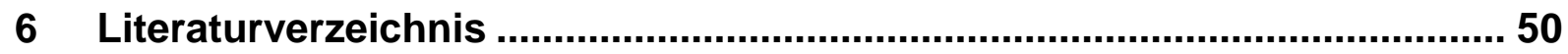

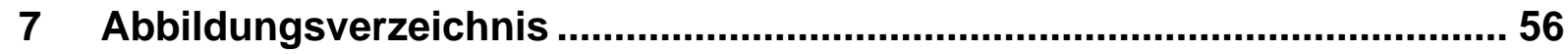

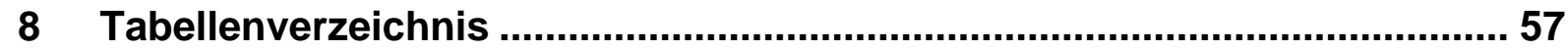




\section{Abkürzungsverzeichnis}

$\begin{array}{ll}\% & \text { Prozent } \\ \text { A.bidest } & \text { 2 mal destilliertes Wasser } \\ \text { A.dest } & \text { Destilliertes Wasser } \\ \text { Abb. } & \text { Abbildung } \\ \text { AFP } & \text { Alpha-Fetoprotein } \\ \text { AP } & \text { Alkalische Phosphatase } \\ \text { B-HCG } & \text { B-humanes Choriongonadotropin } \\ \text { BSA } & \text { Rinderserumalbumin } \\ \text { bzW. } & \text { Beziehungsweise } \\ { }^{\circ} \mathrm{C} & \text { Grad Celsius } \\ \mathrm{Ca} & \text { circa } \\ \mathrm{CC} & \text { Chorionkarzinom } \\ \mathrm{CIN} & \text { Carcinoma in situ } \\ \mathrm{CT} & \text { Computertomographie } \\ \text { d.h. } & \text { das heißt } \\ \text { DAB } & \text { Diaminobenzidin } \\ \mathrm{DST} & \text { Dottersacktumor } \\ \mathrm{EC} & \text { Embryonales Karzinom } \\ \mathrm{EDTA} & \text { Ethylendiamintetraacetat } \\ \mathrm{FCS} & \text { Fötales Kälberserum } \\ \mathrm{g} & \text { Gramm } \\ \mathrm{h} & \text { Stunde } \\ \mathrm{H}{ }_{2} \mathrm{O} & \text { Wasser } \\ \mathrm{H} \mathrm{O}_{2} & \text { Wasserstoffperoxid } \\ \mathrm{HCl} & \text { Salzsäure } \\ \mathrm{HE} & \text { Hämatoxylin-Eosin } \\ \mathrm{IGCNU} & \text { Intratubular Germ Cell Neoplasia, Unclassified } \\ \text { IgG } & \text { Immunglobulin G } \\ \mathrm{K} \mathrm{Al(SO} & \text { Aluminiumkaliumsulfat } \\ \mathrm{KCl} & \text { Kaliumchlorid } \\ \mathrm{kDa} & \text { Kilodalton } \\ \end{array}$




$\begin{array}{ll}\text { I } & \text { Liter } \\ \mu & \text { Mikro } \\ \text { min. } & \text { Molar } \\ \text { MRT } & \text { Minuten } \\ \text { NaCl } & \text { Magnetresonanztomographie } \\ \text { NaOH } & \text { Natriumchlorid } \\ \text { n.u. } & \text { nicht untersucht } \\ \text { Oct-3/4 } & \text { Octamer-binding protein-3/4 } \\ \text { Pan-CK } & \text { Pan-Zytokeratin } \\ \text { PET } & \text { Positronen-Emissions-Tomographie } \\ \text { PLAP } & \text { Plazentare Alkalische Phosphatase } \\ \text { SCF } & \text { Stem Cell Factor } \\ \text { SE } & \text { Seminom } \\ \text { Sox2 } & \text { SRY-Box containing gene 2 } \\ \text { SSW } & \text { Schwangerschaftswoche } \\ \text { Tab. } & \text { Tabelle } \\ \text { TBS } & \text { Tris Buffered Saline } \\ \text { TDS } & \text { Testikuläres Dysgenesie-Syndrom } \\ \text { TE } & \text { Teratom } \\ \text { TGCT } & \text { Testicular Germ Cell Tumor } \\ \text { TIN } & \text { Testikuläre intratubuläre Neoplasie } \\ \text { TMA } & \text { Tissue-Microarray } \\ \text { Tris } & \text { Tris(hydroxymethyl)-aminomethan }\end{array}$




\section{$1 \quad$ Einleitung}

\subsection{Maligne Keimzelltumoren des Hodens}

Maligne Keimzelltumoren des Hodens (TGCT) sind seltene Tumoren $(<1 \%$ aller malignen Neubildungen bei Männern), aber in der Altersklasse zwischen dem 20. und 40. Lebensjahr sind sie die häufigsten bösartigen soliden Tumoren (Ekbom and Akre 1998; Looijenga and Oosterhuis 1999). Die Inzidenz der TGCT beträgt in Deutschland derzeit 9/100.000 männliche Einwohner, weist aber geographisch erhebliche Unterschiede auf. Während die Neuerkrankungsrate in nordeuropäischen Ländern sowie Nordamerika zwischen 8-10/100.000 Männer beträgt, ist sie in asiatischen und afrikanischen Bevölkerungen deutlich niedriger (<2/100.000 Männer) (Krege et al. 2008a; Parkin et al. 2001). Interessanterweise zeigt die Inzidenz der TGCT in den westlichen Industrieländern in den letzten 5 Jahrzehnten aus bisher ungeklärten Gründen einen kontinuierlichen Anstieg (Bokemeyer et al. 1992; Vilar et al. 2006). Als gesicherte Risikofaktoren für die Entwicklung der TGCT gelten der Kryptorchismus, kontralaterale TGCT sowie die familiäre Belastung, wobei das Risiko um das 4-10-fache gesteigert ist. Kontrovers werden weitere Faktoren wie Infertilität, Hodenatrophie, Inguinalhernie, Hodentrauma oder der mütterliche Hormonspiegel diskutiert (Dieckmann and Pichlmeier 2004; Looijenga 2009). Besondere Beachtung fand in jüngster Zeit das testikuläre Dysgenesie-Syndrom (TDS), das sowohl funktionelle Störungen wie abnorme Spermatogenese als auch anatomische Fehlentwicklungen wie Hypospadie und histopathologische Veränderungen wie Mikrolithiasis beinhaltet. (Hoei-Hansen et al. 2003; Skakkebaek et al. 2001). Auch das testikuläre Dysgenesie-Syndrom scheint mit der Entwicklung von TGCT in Verbindung zu stehen (Cools et al. 2006).

Die TGCT werden klinisch und morphologisch, aber auch aufgrund ihres biologischen Verhaltens entsprechend der WHO-Klassifikation in 3 Gruppen unterteilt (Eble et al. 2004). Die Gruppe I der TGCT tritt im 1-4. Lebensjahr auf und beinhaltet Teratome und Dottersacktumoren. Nach der Pubertät manifestieren sich die TGCT der Gruppe II, die in Seminome und Nicht-Seminome unterteilt werden. Das spermatozytäre Seminom, welches in der Regel bei älteren Männern auftritt, bildet die Gruppe III (Looijenga and Oosterhuis 1999; Oosterhuis and Looijenga 2005). 
Teratome der Gruppe I-Tumoren werden als benigne eingestuft und zeigen keine Metastasierung, während die Dottersacktumoren maligne sind und häufig bei Diagnosestellung bereits metastasiert vorliegen (Göbel et al. 2000). Spermatozytäre Seminome der Gruppe III sind sehr selten und in der Regel als gutartige Tumoren einzustufen. Sehr selten können sie in hochmaligne Weichgewebstumoren übergehen (Eble 1994). Die mit Abstand größte Gruppe der TGCT, die Seminome und Nicht-Seminome der Gruppe II, sind allesamt maligne Tumoren. Im Gegensatz zu den TGCT der Gruppe I und III haben die TCGT der Gruppe II eine gemeinsame nicht-invasive Vorläuferläsion, die lange Zeit als atypische Keimzellhyperplasie, Carcinoma in situ (CIS), Seminoma in situ oder testikuläre intratubuläre Neoplasie (TIN) bezeichnet wurde. Nach der aktuellen WHO-Klassifikation soll sie die Bezeichnung intratubuläre Keimzellneoplasie (intratubular germ cell neoplasia unclassified, IGCNU) tragen (Eble et al. 2004; Skakkebaek 1972). Dass die IGCNU die Vorläuferläsion der TGCT darstellt, lässt sich auch daran ablesen, dass sie in der Regel auch in Nachbarschaft zu invasiven TGCT zu finden ist, allerdings häufiger in Verbindung mit nicht-seminomatösen Tumoren als mit Seminomen (Oosterhuis et al. 2003). Die IGCNU repräsentiert eine obligate Präkanzerose, wobei etwa die Hälfte der betroffenen Patienten nach 5 Jahren einen invasiven TGCT entwickelt. Interessanterweise ist die Zeit bis zur Entwicklung eines nicht-seminomatösen TGCT um etwa 10 Jahre kürzer als bei der Entstehung eines seminomatösen Tumors (Hoei-Hansen et al. 2005; van Casteren et al. 2008). Etwa die Hälfte der TGCT der Gruppe II sind Seminome, welche in klassische Seminome, Seminome mit synzytiotrophoblastären Zellen und Seminome mit hoher mitotischer Aktivität unterteilt werden (Eble et al. 2004; Holzik et al. 2008). Die Seminome treten mit einem durchschnittlichen Erkrankungsalter von 37 Jahren auf und zeigen makroskopisch eine homogene grauweiße Schnittfläche mit Nekrosen und Einblutungen. Histologisch sind große runde Zellen mit deutlichem Nukleolus nachweisbar, die von Bindegewebssepten umgeben sind und dichte lymphozytäre Begleitinfiltrate aufweisen. Die Nicht-Seminome, die 40\% der TGCT der Gruppe II ausmachen, werden entsprechend ihrem histologischen Erscheinungsbild und in abfallender Häufigkeit in embryonale Karzinome, Teratome, Dottersacktumoren und Chorionkarzinome unterschieden und treten mit einem mittleren Erkrankungsalter von 27 Jahren auf. Embryonale Karzinome sind makroskopisch häufig kleiner als Seminome, weisen Nekrosen, Blutungen oder Zysten auf und zeigen histologisch 
solide, drüsige oder papilläre Strukturen. Teratome bestehen aus Abkömmlingen aller 3 Keimblätter (Endoderm, Mesoderm, Ektoderm) und zeigen daher histologisch ein „buntes“ Bild. Dottersacktumoren präsentieren eine gelblich schleimige Schnittfläche und mikroskopisch ein heterogenes Bild. Charakteristisch sind die Schiller-Duval-Körperchen, um ein zentrales Blutgefäß angeordnetes Bindegewebe mit atypischen Zellen. Chorionkarzinome sind nicht selten kleine Tumoren, die makroskopisch als hämorrhagische und nekrotische Knötchen imponieren und histologisch zytotrophoblastäre und synzytiotrophoblastäre Zellen zeigen. Die restlichen 10\% der TGCT der Gruppe II machen Mischtumoren aus, die sowohl seminomatöse als auch nicht-seminomatöse Komponenten enthalten (Böcker et al. 2008; Eble et al. 2004; Honecker et al. 2004; Kumar et al. 2009; Riede et al. 2004). Neben dem Hoden als Primärlokalisation können TGCT in seltenen Fällen auch korrespondierend zu der embryonalen Wanderungsstrecke primordialer Keimzellen entlang der Mittellinie des Körpers retroperitoneal, mediastinal oder im Gehirn auftreten (Honecker et al. 2004). TGCT werden klinisch meist durch eine schmerzlose Hodenschwellung auffällig. Wesentlich seltener treten eine schmerzhafte Hodenschwellung oder Symptome wie Rückenschmerzen, Dyspnoe oder eine retroperitoneale, mediastinale oder supraklavikuläre Raumforderung, die durch eine Metastasierung hervorgerufen werden, auf. Die Prognose für Patienten mit einem malignen Keimzelltumor des Hodens ist sehr gut, was im Wesentlichen auf die hohe Chemo- und Radiosensitivität der TGCT zurückzuführen ist. So beträgt die 5-Jahres-Überlebensrate bei nicht metastasierten Tumoren über 95\% und bei bereits metastasierten Tumoren etwa 80\% (Krege et al. 2008a; Krege et al. 2008b).

\subsection{Immunhistochemische Diagnostik maligner Keimzelltumoren des Hodens}

Neben der Morphologie sind für die exakte Diagnose der TGCT immunhistochemische Untersuchungen notwendig. Durch Anwendung unterschiedlicher Tumor-spezifischer Antikörper können die einzelnen histologischen Entitäten der TGCT als auch die IGCNU diagnostiziert werden. In der Vergangenheit wurden bereits einzelne immunhistochemische Marker zur Diagnostik von malignen Keimzelltumoren des Hodens etabliert und angewandt, wobei Pan-Zytokeratin (Pan- 
CK), die plazentare alkalische Phosphatase (PLAP), CD 30, $\alpha$-Fetoprotein (AFP) und $\beta$-humanes Choriongonadotropin ( $\beta$-HCG) die bekanntesten Vertreter darstellen.

Zytokeratin ist ein zytoplasmatisch lokalisiertes Intermediärfilament, das im Zytoskelett epithelialer Zellen exprimiert wird. In unterschiedlichen Studien konnte gezeigt werden, dass embryonale Karzinome, Teratome, Dottersacktumoren und Chorionkarzinome eine Expression von Zytokeratin zeigen, wohingegen die Expression von Zytokeratin in Seminomen heterogen beschrieben wird. (Battifora et al. 1984; Eglen and Ulbright 1987; Fogel et al. 1990; Miettinen et al. 1985).

PLAP ist ein membrangebundenes Glykoprotein, das physiologisch von der Plazenta produziert wird. Als einer der ersten Marker wurde PLAP in TGCT untersucht und die durchgeführten Studien zeigten, dass IGCNU und Seminome eine Expression der PLAP zeigen. Auch für embryonale Karzinome wurde partiell eine Expression der PLAP beschrieben, während Dottersacktumoren und Chorionkarzinome ein heterogenes Bild präsentierten und Teratome nur in wenigen Einzelfällen eine Anfärbbarkeit zeigten (Beckstead 1983; Burke and Mostofi 1988; Paiva et al. 1983; van Casteren et al. 2008; Wick et al. 1987).

CD 30 ist ein Mitglied der Tumor-Nekrosefaktor-Familie, welches 1982 von Schwab et al. als Marker der Hodgkin- und Reed-Sternberg-Zellen eines klassischen Hodgkin-Lymphoms beschrieben wurde. In zahlreichen Studien wurde nachgewiesen, dass embryonale Karzinome ebenfalls CD 30 exprimieren. Alle anderen histologischen Entitäten der TGCT inklusive der IGCNU zeigen keine Expression von CD 30 (Gopalan et al. 2009; Lau et al. 2007; Leroy et al. 2002; Schwab et al. 1982).

AFP ist ein Glykoprotein, das normalerweise vom Dottersack sowie der fötalen Leber und dem Gastrointestinaltrakt produziert wird. Darüberhinaus ist bekannt, dass AFP ebenso wie ß-HCG ein Serummarker für TGCT darstellt. Dottersacktumoren zeigen immunhistochemisch in der Regel eine Expression von AFP. Interessanterweise ist für wenige Fälle eines embryonalen Karzinoms eine Expression von AFP festgestellt worden (de Matteis and Silverio 1987; Eglen and Ulbright 1987; Jacobsen and Jacobsen 1983; Morinaga et al. 1983).

ß-HCG ist ein von Synzytiotrophoblasten produziertes Glykoprotein und dient als klassischer Tumormarker bei TGCT. Mehrere immunhistochemische Studien zeigten eine Expression von ß-HCG in Chorionkarzinomen, wohingegen Seminome und embryonale Karzinome keine Expression zeigten. Es ist jedoch bekannt, dass 
Seminome mit synzytiotrophoblastären Zellen eine Expression von ß-HCG in den Synzytiotrophoblasten zeigen (de Matteis and Silverio 1987; Morinaga et al. 1983).

In jüngster Zeit wurden weitere neue immunhistochemische Marker für die Diagnostik von malignen Keimzelltumoren des Hodens in kleinen Fallserien und nicht für alle histologischen Entitäten beschrieben, die im Nachfolgenden vorgestellt werden sollen.

Oct-3/4 (Octamer-binding protein-3/4, Synonym: POU domain class 5, transcription factor 1, POU5F1) ist ein Transkriptionsfaktor, der für die Pluripotenz embryonaler Stammzellen von entscheidender Bedeutung ist. Verschiedene Studien an kleineren Fallserien haben gezeigt, dass Oct-3/4 ein zuverlässiger Marker für die Diagnostik von IGCNU, Seminomen und embryonalen Karzinomen ist. Im Gegensatz dazu konnte für alle anderen histologischen Entitäten der TGCT keine Expression von Oct3/4 nachgewiesen werden. (de Jong et al. 2005; Gopalan et al. 2009; Looijenga et al. 2003; Santagata et al. 2007).

Sox2 (SRY-box containing gene 2) gehört zur Familie der Sox-Proteine und ist ein weiterer Transkriptionsfaktor, der neben Oct-3/4 in der Entwicklung embryonaler Stammzellen eine zentrale Rolle spielt. In wenigen immunhistochemischen Untersuchungen konnte nachgewiesen werden, dass embryonale Karzinome und epitheliale Tumoranteile eines Teratoms eine Expression von Sox2 besitzen. Desweiteren konnte eine Expression von Sox2 in Sertoli-Zellen beobachtet werden (de Jong et al. 2008; Gopalan et al. 2009; Santagata et al. 2007).

CD 117 (c-kit) ist eine Rezeptor-Tyrosinkinase und in vielen Studien in Verbindung mit TGCT untersucht worden. In diesen Studien ist eine deutliche Expression von CD 117 in IGCNU sowie Seminomen festgestellt worden, während nicht-seminomatöse Tumoren nur in einzelnen Fällen eine Expression zeigten (Gopalan et al. 2009; Lau et al. 2007; Leroy et al. 2002; Rajpert-De Meyts and Skakkebaek 1994).

Podoplanin ist ein Muzin-ähnliches Glykoprotein, welches von einer Vielzahl unterschiedlicher Zelltypen (u.a. Endothelien von Lymphgefäßen und Mesothelzellen) exprimiert wird und von dem monoklonalen Antikörper D2-40 erkannt wird. Seminome und IGCNU zeigten in den wenigen bisher vorliegenden Studien eine Expression von D2-40, während Nicht-Seminome keine oder nur eine vereinzelte Expression von D2-40 zeigten (Lau et al. 2007; Marks et al. 1999; Sonne et al. 2006; Yu et al. 2007). 
CD 9 ist ein Mitglied der Tetraspanin-Familie, die transmembranöse Glykoproteine repräsentieren. Es existiert nur eine Studie über immunhistochemische Untersuchungen von CD 9 in Verbindung mit TGCT. Diese zeigte eine Expression von CD 9 in IGCNU, Seminomen und embryonalen Karzinomen. Die Expression von CD 9 in anderen nicht-seminomatösen Tumoren ist bisher nicht untersucht worden (Biermann et al. 2007b; Kanatsu-Shinohara et al. 2004; Kawashima et al. 2002).

Tabelle 1 zeigt eine Übersicht über die Antikörper und ihre immunhistochemische Expression in TGCT, wie sie in der zitierten Literatur beschrieben wurde.

Tabelle 1: Immunhistochemisches Expressionsprofil von TGCT

\begin{tabular}{|cccccccccccc|}
\hline Histologie & & & & & Marker & & & & \\
IGCNU & Pan-CK & PLAP & CD 30 & AFP & B-HCG & Oct-3/4 & Sox2 & CD 117 & D2-40 & CD 9 \\
SE & + & + & - & - & - & + & - & + & + & + \\
EC & $+/-$ & + & - & - & - & + & - & + & + & + \\
TE & + & + & + & $-/+$ & - & + & + & - & $-/+$ & + \\
DST & + & - & - & - & - & - & $+/-$ & - & $-/+$ & n.u. \\
CC & + & $+/-$ & - & + & - & - & - & - & $-/+$ & n.u. \\
\end{tabular}

$+=$ positive Expression, -= negative Expression, +/-= heterogenes Expressionsprofil, n.u.= nicht untersucht

\subsection{Die Tissue-Microarray-Technik}

Tissue-Microarrays (TMAs) sind Paraffin-Gewebeblöcke, die nicht nur Gewebe von einem Patienten enthalten, sondern in Form kleiner Stanzzylinder Gewebe von vielen verschiedenen Patienten. Erstmals beschrieben wurde diese Technik 1986 und in den nachfolgenden Jahren wurde sie weiterentwickelt und modifiziert (Battifora 1986; Kononen et al. 1998). Je nach Gewebebeschaffenheit und anzustrebender Untersuchungstechnik ist es möglich, bis zu 1000 und auch mehr Gewebeproben auf einen Paraffinblock zu übertragen und Untersuchungen daran vorzunehmen. Neben der Immunhistochemie, die in dieser Arbeit in Verbindung mit TMAs angewendet wurde, ist es auch möglich, andere Untersuchungstechniken wie die Fluoreszenz-insitu-Hybridisierung anzuwenden (Skacel et al. 2002). Gegenüber der bisher durchgeführten Untersuchung von einzelnen Gewebeblöcken hat die TMA-Technik den Vorteil, eine große Probenanzahl durch vergleichsweise wenig Aufwand und 
Kosten zu untersuchen. Darüber hinaus unterliegen alle Gewebeproben eines TMA den gleichen Untersuchungsbedingungen, wodurch eine direkte Vergleichbarkeit des Gewebes gewährleistet ist. Durch Entnahme von Gewebezylindern von nur wenigen Millimetern Durchmesser wird der Originalgewebeblock nur gering zerstört und kann zu einem späteren Zeitpunkt für weitere Untersuchungen genutzt werden (Kononen et al. 1998). Als ein Nachteil dieser Methode wurde diskutiert, ob eine Gewebeprobe von so geringem Durchmesser einen Tumor in seiner ganzen Heterogenität repräsentieren kann. Mehrere Studien konnten dieses Argument entkräften, allerdings wurde empfohlen, zur Erzielung der Repräsentativität, pro Gewebeblock mehr als eine Stanze zu entnehmen (Camp et al. 2000). Ein weiterer Nachteil ist das Verschwinden einzelner Stanzen auf dem später angefertigten Schnittpräparat durch Schneiden des Paraffin-Gewebeblocks sowie weiterer Prozeduren, denen der Schnitt durch Untersuchungsmethoden obliegt (Jawhar 2009; Voduc et al. 2008).

\section{$1.4 \quad$ Zielsetzung}

Das Ziel der vorliegenden Arbeit war es, bereits bekannte und etablierte als auch neue immunhistochemische Marker für die Diagnostik maligner Keimzelltumoren des Hodens anhand eines großen Patientenkollektivs mittels Tissue-Microarrays zu untersuchen und einen immunhistochemischen Algorithmus für die Diagnostik von TGCT zu entwickeln. 


\section{Material und Methoden}

\subsection{Material}

Die in Paraffinblöcke eingebetteten Gewebeproben wurden freundlicherweise von der Abteilung Pathologie des Universitätsklinikums Göttingen zur Verfügung gestellt.

\subsubsection{Verwendete Geräte}

\begin{tabular}{|l|l|}
\hline Gerät & Hersteller \\
\hline Arrayer Booster & Alphelys, Plaisir, Frankreich \\
\hline Dampfgarer Multi-Gourmet & Braun, Melsungen, Deutschland \\
\hline Digitale Farbkamera DP20 & Olympus, Hamburg, Deutschland \\
\hline Kühlplatte & $\begin{array}{l}\text { Kunz Instruments, Nynäshamn, } \\
\text { Dänemark }\end{array}$ \\
\hline Kühl- und Gefrierkombination & Bosch, München, Deutschland \\
\hline Lichtmikroskop BX 41 & Olympus, Hamburg, Deutschland \\
\hline Magnetrührer RH & IKA, Staufen, Deutschland \\
\hline Manueller Tissue Arrayer MTA-1 & Alphelys, Plaisir, Frankreich \\
\hline $\begin{array}{l}\text { Paraffin-Ausgießstation Tissue Block } \\
\text { Dispenser PAG12 }\end{array}$ & Medite, Burgdorf, Deutschland \\
\hline pH-Meter CG 811 & Schott AG, Hofheim, Deutschland \\
\hline Plattformschüttler Polymax 1040 & Heidolph, Schwabach, Deutschland \\
\hline Programm TMADesigner & Alphelys, Plaisir, Frankreich \\
\hline Recipient Block Carousel & Alphelys, Plaisir, Frankreich \\
\hline Schlittenmikrotom HM 400 & Microm GmbH, Walldorf, Deutschland \\
\hline Wärmeplatte & Medite, Burgdorf, Deutschland \\
\hline Wärmeschrank 37,5C Function Line & Heraeus, Hanau, Deutschland \\
\hline
\end{tabular}




\subsubsection{Verwendete Gebrauchsmaterialien}

\begin{tabular}{|l|l|}
\hline Material & Hersteller \\
\hline Ausgießförmchen & $\begin{array}{l}\text { Leica Microsystems, Wetzlar, } \\
\text { Deutschland }\end{array}$ \\
\hline Deckplättchen & $\begin{array}{l}\text { Menzel-Gläser, Braunschweig, } \\
\text { Deutschland }\end{array}$ \\
\hline Einbettkassetten & $\begin{array}{l}\text { Kabe-Labortechnik, Nümbrecht- } \\
\text { Elsenroth, Deutschland }\end{array}$ \\
\hline Fettstift Super Pap Pen & Daldo Sangyo Co, Tokyo, Japan \\
\hline Objektträger & $\begin{array}{l}\text { Knittel-Gläser, Braunschweig, } \\
\text { Deutschland }\end{array}$ \\
\hline Objektträger SuperFrost Plus & $\begin{array}{l}\text { Menzel-Gläser, Braunschweig, } \\
\text { Deutschland }\end{array}$ \\
\hline
\end{tabular}

\subsubsection{Verwendete Molekularbiologische Agenzien}

\begin{tabular}{|l|l|}
\hline Agens & Hersteller \\
\hline Alkohol 100\%, 96\%, 70\% & Chemie-Vertrieb, Hannover, Deutschland \\
\hline Aluminiumkaliumsulfat & Merck, Darmstadt, Deutschland \\
\hline AP Substratpuffer & Dako, Hamburg, Deutschland \\
\hline A.bidest & Roth, Karlsruhe, Deutschland \\
\hline Aquamount & Merck, Darmstadt, Deutschland \\
\hline BSA (Rinderserumalbumin) & Roth, Karlsruhe, Deutschland \\
\hline Chloralhydrat & Merck, Darmstadt, Deutschland \\
\hline Chromogen Red 1 & Dako, Hamburg, Deutschland \\
\hline Chromogen Red 2 & Dako, Hamburg, Deutschland \\
\hline Chromogen Red 3 & Dako, Hamburg, Deutschland \\
\hline Citronensäure-Monohydrat & Merck, Darmstadt, Deutschland \\
\hline DAB-Chromogen & Dako, Hamburg, Deutschland \\
\hline Diluent & Dako, Hamburg, Deutschland \\
\hline EDTA & Sigma-Aldrich, Taufkirchen, Deutschland \\
\hline Envision & Dako, Hamburg, Deutschland \\
\hline FCS (fötales Kälberserum) & PAA, Pasching, Österreich \\
\hline $\mathrm{H}_{2} \mathrm{O}_{2}$ 30\% & Merck, Darmstadt, Deutschland \\
\hline
\end{tabular}




\begin{tabular}{|c|c|}
\hline Hämatoxylin & Merck, Darmstadt, Deutschland \\
\hline $\mathrm{HCl} 37 \%$ & Merck, Darmstadt, Deutschland \\
\hline $\mathrm{KCl}$ & Merck, Darmstadt, Deutschland \\
\hline Levamisole (X501) & Dako, Hamburg, Deutschland \\
\hline Link, Biotinylierter Sekundärantikörper & Dako, Hamburg, Deutschland \\
\hline $\mathrm{NaCl}$ & Merck, Darmstadt; Deutschland \\
\hline $\mathrm{NaOH}$ & Merck, Darmstadt, Deutschland \\
\hline Natriumjodat & Merck, Darmstadt, Deutschland \\
\hline Paraffin & Süsse, Gudensberg, Deutschland \\
\hline Primärantikörper anti-AFP & Dako, Hamburg, Deutschland \\
\hline Primärantikörper anti-CD 117 & Dako, Hamburg, Deutschland \\
\hline $\begin{array}{l}\text { Primärantikörper anti-CD 30, } \\
\text { Klon Ber-H2 }\end{array}$ & Dako, Hamburg, Deutschland \\
\hline $\begin{array}{l}\text { Primärantikörper anti-CD 9, } \\
\text { Klon } 72 \text { F6 }\end{array}$ & Novocastra, Newcastle, UK \\
\hline $\begin{array}{l}\text { Primärantikörper anti-D2-40, } \\
\text { Klon D2-40 }\end{array}$ & Dako, Hamburg, Deutschland \\
\hline Primärantikörper anti-Oct-3/4 & Santa Cruz, Heidelberg, Deutschland \\
\hline $\begin{array}{l}\text { Primärantikörper anti-Pan-CK, } \\
\text { Klon MNF116 }\end{array}$ & Dako, Hamburg, Deutschland \\
\hline $\begin{array}{l}\text { Primärantikörper anti-PLAP, } \\
\text { Klon 8A9 }\end{array}$ & Dako, Hamburg, Deutschland \\
\hline Primärantikörper anti-Sox2 & R\&D Systems, Minneapolis, USA \\
\hline Primärantikörper anti-ß-HCG & Dako, Hamburg, Deutschland \\
\hline Proteinase XXIV & Sigma-Aldrich, Taufkirchen, Deutschland \\
\hline Sekundärantikörper horse anti-goat lgG & Vector, Burlingame, USA \\
\hline Streptavidin AP & Dako, Hamburg, Deutschland \\
\hline Tri-Natriumcitrat-Dihydrat & Merck, Darmstadt, Deutschland \\
\hline Tris & Roth, Karlsruhe, Deutschland \\
\hline Xylol & Mallinckrodt Baker, Deventer, Holland \\
\hline
\end{tabular}




\subsection{Methoden}

\subsubsection{Zusammenstellung des Patientenkollektivs}

Anhand einer Diagnoseliste aus den Jahren 2002 bis 2007 der Abteilung Pathologie des Universitätsklinikums Göttingen wurden 204 männliche Patienten mit der Diagnose „Maligner Keimzelltumor des Hodens" ausgewählt, bei denen im Rahmen ihrer Tumorerkrankung eine Orchiektomie in der Abteilung Urologie, Universitätsmedizin Göttingen, durchgeführt wurde. Aufgrund der geringen Anzahl an Dottersacktumoren und Chorionkarzinomen wurden einzelne Fälle dieser Tumorentitäten aus den Jahren 1994 bis 2001 hinzugenommen. Die im Schnittarchiv vorliegenden HE-Schnittpräparate wurden hinsichtlich ihres Tumoranteiles ausgewählt und die entsprechenden repräsentativen Tumorareale auf den Schnittpräparaten markiert. Anhand dieser wurden die entsprechenden Paraffingewebeblöcke aus dem Archiv der Pathologie herausgesucht. Zusätzlich wurden relevante Daten (Alter, Diagnose, Tumorstadium, Lokalisation) aus den Befunden der Patienten erhoben. Jeder Patient bekam anhand einer erstellten Liste eine Nummer zugeteilt, die das Zuordnen zu den einzelnen TMA-Stanzen erleichterte.

\subsubsection{Herstellung der Tissue-Microarrays (TMAs )}

Tissue- Microarrays sind Gewebeblöcke, die eine große Anzahl an Gewebeproben in Form kleiner Stanzzylinder enthalten. Anhand dieser kann ein großes Kollektiv für eine bestimmte Untersuchungsmethode beurteilt werden.

Zur Vorbereitung eines TMA wurde ein Daten-Stick, der TMA Booster Key, mit dem Software-Programm „TMA Designer" auf einem Computer installiert. Das Programm übertrug Koordinaten eines vorgegebenen Rasters auf den Stick. Nachdem der Stick an den manuellen Tissue Arrayer angeschlossen war, erleichterte er bei der Herstellung des TMAs das exakte Justieren der Stanzen auf dem Paraffin-Leerblock, indem er den Abstand zwischen den einzelnen Stanzen immer gleich wählte. 
Nach Anschließen des TMA Booster Keys an den manuellen Tissue Arrayer erfolgte das Befestigen eines Paraffin-Leerblocks, dem Empfängerblock, in dem dafür vorhergesehen Halter (Abb. 1).

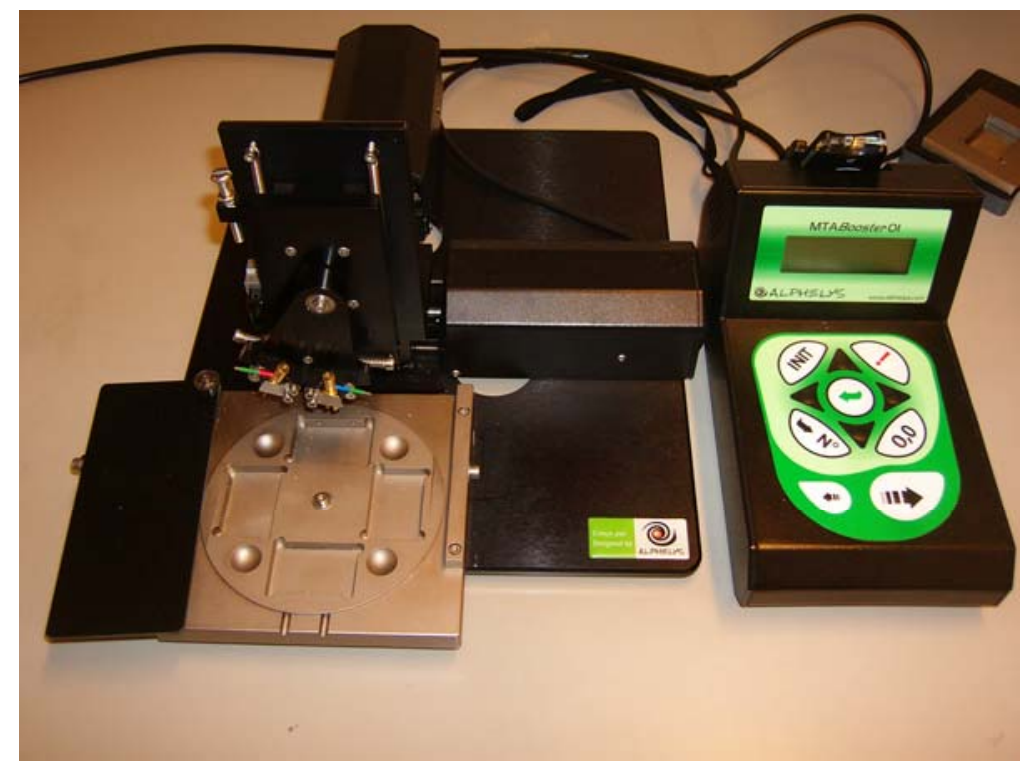

Abbildung 1: Manueller Tissue Arrayer mit TMA Booster Key und Halteapparat für den Leerblock

Vor Beginn der Herstellung des TMAs wurde die Nullposition, die der Stanze A1 entsprach, manuell festgelegt. Anhand einer vorher angelegten Tabelle konnte exakt jeder Stanze eine Patientennummer zugeordnet werden. Die Tabelle enthielt ein Raster von Spalte 1 bis 11 und Zeile $A$ bis $H$. Die Spalte 1 A-H diente als Kontrollreihe mit Gewebe von Milz, Leber und Lunge sowie 2 Leerstellen zur Orientierung (Beispiel in Tabelle 2).

Tabelle 2: Tabellenraster für die Zuordnung des TMA „N2“

\begin{tabular}{|c|c|c|c|c|c|c|c|c|c|c|c|}
\hline $\begin{array}{l}\text { Zeile } \\
\text { Spalte }\end{array}$ & 1 & 2 & 3 & 4 & 5 & 6 & 7 & 8 & 9 & 10 & 11 \\
\hline A & Lunge & 106 & 106 & 106 & $106 n 2$ & $106 n 2$ & 110 & 110 & 110 & $111 a$ & $111 a$ \\
\hline B & Lunge & $111 a$ & $112 n$ & $112 n$ & $112 n$ & $114 a$ & $114 a$ & $114 a$ & 116n1 & $116 \mathrm{n} 2$ & $116 \mathrm{n} 2$ \\
\hline C & Leber & 119n1 & $119 \mathrm{n} 2$ & $119 b$ & $119 b$ & $119 b$ & 120n1 & 120n2 & $121 n$ & $121 n$ & $121 n$ \\
\hline D & Leber & $124 n$ & $124 n$ & $124 n$ & 128n1 & $128 n 2$ & $128 n 2$ & 129n1 & 129n1 & $129 n 2$ & 141n1 \\
\hline$E$ & Milz & 141n1 & $141 \mathrm{n} 2$ & $143 a$ & $143 a$ & $143 a$ & $147 n$ & $147 n$ & 155n1 & 155n1 & $155 n 2$ \\
\hline$F$ & Milz & 158n1 & 158n1 & $158 n 2$ & $161 a$ & $161 a$ & $161 a$ & 161n1 & $161 \mathrm{n} 2$ & $162 \mathrm{n} 1$ & $162 n 2$ \\
\hline G & leer & $163 n 1$ & $163 n 2$ & $164 \mathrm{n} 1$ & $164 \mathrm{n} 1$ & $164 n 2$ & $164 \mathrm{n} 2$ & $164 a$ & $164 a$ & $164 b$ & $165 n 1$ \\
\hline $\mathrm{H}$ & leer & $171 n$ & 175n1 & $175 n 1$ & $175 \mathrm{n} 2$ & 176n1 & $176 \mathrm{n} 2$ & $176 n 2$ & $178 n 2$ & 182 & 182 \\
\hline
\end{tabular}


Der manuelle Tissue-Arrayer enthält 2 verschiedenfarbige Stanzen (blau und rot). Die beiden Stanzen haben einen unterschiedlichen Durchmesser. Der Durchmesser der blauen Stanze ist größer, um die Wanddicke der roten Stanze auszugleichen. Verwendet wurde ein blauer Stanzendurchmesser von $1 \mathrm{~mm}$. Nun folgte für jeden Stanzzylinder derselbe Vorgang: mit der kleineren roten Stanze wurde ein Loch in den Empfängerblock gestanzt. Anschließend wurde mit der blauen Stanze aus dem Spenderblock eine markierte Gewebeprobe entnommen und in das Loch des Empfängerblockes übertragen (Abb. 2).

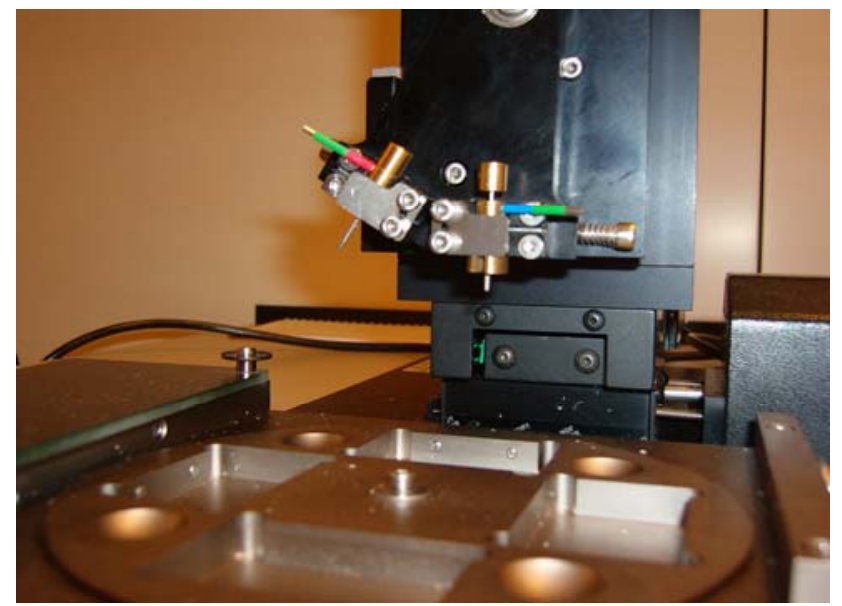

Abbildung 2: Stanzvorrichtung des manuellen Tissue-Arrayers mit Halteapparatur für den Leerblock

Dieser Vorgang wurde so oft wiederholt, bis alle Stanzen entsprechend der vorher angelegten Tabelle auf dem Empfängerblock platziert waren. Nach Fertigstellen des TMAs wurde dieser für $30 \mathrm{~min}$ in einem Wärmeschrank bei $37^{\circ} \mathrm{C}$ inkubiert. Außerdem wurde der Paraffinblock mit Druck von oben und der Seite nachgeformt, um die Stanzen in eine Ebene zu bringen. Anschließend erfolgte ein erneutes Erwärmen des TMAs in einem Ausgießförmchen, das etwas Paraffin enthielt. Das Erwärmen fand auf einer Wärmeplatte bei $65^{\circ} \mathrm{C}$ für 15 min statt. Abschließend kühlte der TMA auf einer Kühlplatte ab. Diese Vorgänge dienten dazu, eine bessere Verbindung zwischen den einzelnen Gewebestanzen und dem umgebenden Paraffinblock zu bewirken. Auf diese Weise wurden 17 TMAs hergestellt (Abb. 3). 


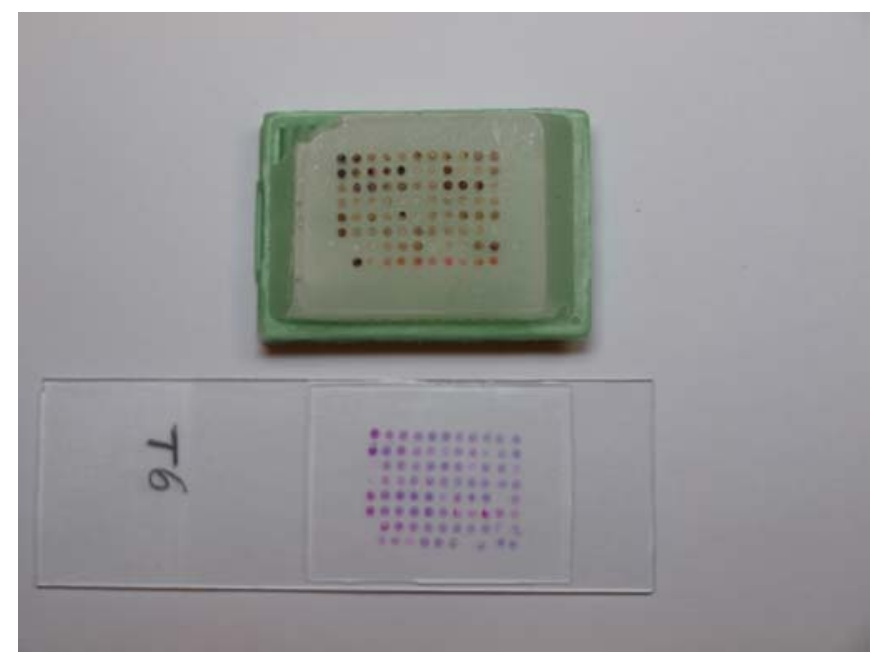

Abbildung 3: Beispiel eines TMAs und des korrespondierenden HE-Schnittes

\subsubsection{Herstellung von Paraffinschnitten}

Die TMAs wurden mit einem Schlittenmikrotom in $2 \mu \mathrm{m}$ dicke Paraffinschnitte geschnitten und diese auf silanisierte Objektträger aufgetragen. Die silanisierten Objektträger dienten zur besseren Oberflächenhaftung des aufgebrachten Paraffinschnittes. Zur Erhaltung der Antigenstruktur wurden die hergestellten Paraffinschnitte über Nacht in einem Wärmeschrank bei $37^{\circ} \mathrm{C}$ getrocknet. Anschließend waren sie bereit für die immunhistochemischen Färbungen. Zur Kontrolle der hergestellten TMAs wurden von den ersten Paraffinschnitten HEFärbungen angefertigt.

\subsubsection{Immunhistochemie}

Die immunhistochemischen Anfärbungen beruhen auf einer Antigen-AntikörperReaktion. Mittels spezifischer Antikörper lassen sich so in Paraffin eingebettete Gewebe in unterschiedliche Gewebstypen oder Tumorentitäten bestimmen. Die Antigen-Antikörper-Bindung lässt sich durch unterschiedliche Detektionssysteme visualisieren. 
Die Paraffinschnitte wurden 2x10 min. in Xylol entparaffiniert, über eine absteigende Alkoholreihe (100\%, 96\% und 70 \% Ethanol) für jeweils 2 min. rehydriert und dann in A.dest. für 3 min. gespült. Zur Antikörper-Demaskierung wurden die Schnittpräparate in Citratpuffer pH 6,0 oder EDTA pH 8,0 für 40 min. im Dampfgarer inkubiert (Tab. 3 und 4). Alternativ erfolgte eine Vorverdauung der Schnittpräparate mit Protease XXIV für 15 min. Hiernach wurden die Schnittpräparate für 5 Minuten mit destilliertem Wasser und nachfolgend Tris-bufferd Saline (TBS) gespült (Tab. 5). Anschließend wurde die endogene Peroxidase und unspezifische Antikörperbindungen mit 3\% $\mathrm{H}_{2} \mathrm{O}_{2}$ in TBS bzw. 10\%BSA/5\%FCS in TBS für jeweils 20 min. blockiert. Nach Spülen in TBS für 10 min. erfolgte die Inkubation mit dem Primärantikörper in TBS für $1 \mathrm{~h}$. Nach Spülen in TBS für $2 \times 2$ min. wurden die Schnittpräparate mit dem EnVisionDetektionssystem für $30 \mathrm{~min}$. inkubiert und anschließend in TBS für $2 \times 2 \mathrm{~min}$ gespült. Die Antigen-Antikörper-Reaktion wurde mittels DAB-Chromogen (20 min., Verdünnung 1:50 in Diluent) sichtbar gemacht. Als alternatives Detektionssystem fand ein Streptavidin-konjugierter Sekundärantikörper bzw. das Link/Label-System Anwendung. Hierzu wurden die Schnittpräparate nach Primärantikörper-Behandlung mit dem Sekundärantikörper ( horse anti-goat ) bzw. Link für 30 min. inkubiert, für $2 x$ 2 min. in TBS gespült und mit Streptavidin für $30 \mathrm{~min}$. behandelt. Nach Spülen in TBS für $2 \times 2$ min. wurde die Antigen-Antikörper-Reaktion mittels Fast-Red-

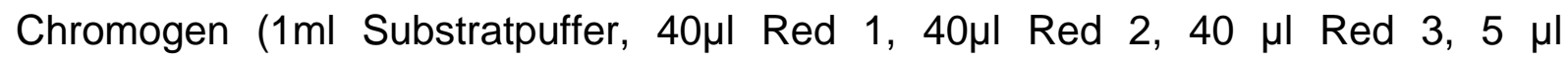
Levamisol) für 20 min. sichtbar gemacht. Nach Stoppen der Färbereaktion mit TBS wurden die Schnittpräparate mit A.dest. gespült, mit Hämalaun (Tabelle 6) für 7 min. gegengefärbt und unter warmem Leitungswasser gebläut. Die Schnittpräparate wurden zuletzt in Aquamount eingedeckt.

Die angewandten Antikörper, Verdünnungen, Vorbehandlungs- und Färbemethoden sowie Detektionssysteme sind in Tabelle 7 und 8 zusammengefasst.

Tabelle 3: Citratpuffer pH 6,0

\begin{tabular}{|ll|}
\hline Citratpuffer $\mathbf{p H}$ 6,0 & \\
\hline 0,1M Citronensäure & $18 \mathrm{ml}$ \\
$0,1 \mathrm{M}$ Natriumcitrat & $82 \mathrm{ml}$ \\
A.dest & $900 \mathrm{ml}$ \\
\hline
\end{tabular}


Tabelle 4: EDTA pH 8,0

\begin{tabular}{|ll|}
\hline EDTA pH 8,0 & \\
\hline EDTA & $0,3722 \mathrm{~g}$ \\
Aqua bidest & $900 \mathrm{ml}$ \\
Einstellen des pH mit $\mathrm{NaOH}$ & \\
\hline
\end{tabular}

Tabelle 5: Tris-buffered Saline (TBS) pH 7,4

\begin{tabular}{|ll|}
\hline TBS (Tris-buffered Saline) \\
\hline Tris & $12,11 \mathrm{~g}$ \\
$\mathrm{NaCl}$ & $17,53 \mathrm{~g}$ \\
Einstellen des $\mathrm{pH}$ mit 37\% HCl & \\
\hline
\end{tabular}

Tabelle 6: Hämalaun

\begin{tabular}{|ll|}
\hline Hämalaun \\
\hline Hämatoxylin & $1 \mathrm{~g}$ \\
$\mathrm{~K} \mathrm{Al}\left(\mathrm{SO}_{4}\right) 12 \mathrm{H}_{2} \mathrm{O}$ & $50 \mathrm{~g}$ \\
Natriumjodat & $0,2 \mathrm{~g}$ \\
Chloralhydrat & $30 \mathrm{~g}$ \\
Citronensäure & $1 \mathrm{~g}$ \\
Aqua dest. & $1 \mathrm{I}$ \\
\hline
\end{tabular}

Tabelle 7: Antikörperverdünnung, Antigendemaskierung und Färbemethode

\begin{tabular}{|llll|}
\hline Antikörper & Verdünnung & Antigendemaskierung & Färbemethode \\
\hline Pan-CK & $1: 400$ & Protease & DAB-Chromogen \\
& & & Fast-Red-Chromogen \\
PLAP & $1: 50$ & Dampfgarer, Citratpuffer & DAB-Chromogen \\
CD 30 & $1: 30$ & Dampfgarer, Citratpuffer & Fast-Red-Chromogen \\
AFP & $1: 600$ & keine & DAB-Chromogen \\
B-HCG & $1: 1000$ & keine & DAB-Chromogen \\
Oct-3/4 & $1: 200$ & Dampfgarer, Citratpuffer & Fast-Red-Chromogen \\
Sox2 & $1: 100$ & Dampfgarer, Citratpuffer & Fast-Red-Chromogen \\
CD 117 & $1: 400$ & Dampfgarer, Citratpuffer & DAB-Chromogen \\
D2-40 & $1: 150$ & Dampfgarer, Citratpuffer & DAB-Chromogen \\
CD 9 & $1: 50$ & Dampfgarer, EDTA & DAB-Chromogen \\
\hline
\end{tabular}


Tabelle 8: Detektionssysteme

\begin{tabular}{|ll|}
\hline Antikörper & Detektionssystem \\
\hline Pan-CK & Envision, Link/Label-System \\
PLAP & Envision \\
CD $\mathbf{3 0}$ & Link/Label-System \\
AFP & Envision \\
B-HCG & Envision \\
Oct-3/4 & Streptavidin-konjugierter Sekundärantikörper (horse anti-goat IgG, 1:200 in TBS) \\
Sox2 & Streptavidin-konjugierter Sekundärantikörper (horse anti-goat IgG, 1:200 in TBS) \\
CD 117 & Envision \\
D2-40 & Envision \\
CD 9 & Envision \\
\hline
\end{tabular}

\subsubsection{Auswertung}

Die Auswertung der TMA-Schnitte wurde an einem Lichtmikroskop des Typs Olympus BX 41 vorgenommen. Jeder einzelne Dot wurde untersucht und ausgewertet, wobei „+" ein positives Ergebnis, d.h. eine Expression des jeweiligen Antikörpers und "," ein negatives Ergebnis kennzeichnete. Die Kontrollreihe mit Milz-, Lungen- und Lebergewebe diente als Orientierung. 


\section{Ergebnisse}

\subsection{Patientenkollektiv}

Das Patientenkollektiv rekrutierte sich aus einer Liste von männlichen Patienten, die in den Jahren 2002 bis 2007 im Zentrum Pathologie, Universitätsmedizin Göttingen, mit der Diagnose „Maligner Keimzelltumor des Hodens“ geführt wurden. Aufgrund der geringen Anzahl von Chorionkarzinomen und Dottersacktumoren wurden einzelne Patienten aus den Jahren 1994 bis 2001 hinzugefügt. Aus dieser Liste wurden ursprünglich 204 Patienten ausgewählt, wobei 30 Patienten aus unterschiedlichen Gründen herausfielen. Somit konnte das in Formalin fixierte und in Paraffin eingebettete Gewebsmaterial von 174 Patienten zur Anfertigung von TissueMicroarrays verwendet und mittels anschließender Immunhistochemie untersucht werden.

Die männlichen Patienten hatten zum Diagnosezeitpunkt ein Durchschnittsalter von 36,8 Jahren (1-76 Jahre). Das durchschnittliche Erkrankungsalter der Patienten mit der Diagnose Seminom betrug 38,6 Jahre, wohingegen die Patienten mit der Diagnose eines Nicht-Seminoms im Durchschnitt $(34,7$ Jahre) etwas früher erkrankten (Abbildung 4).

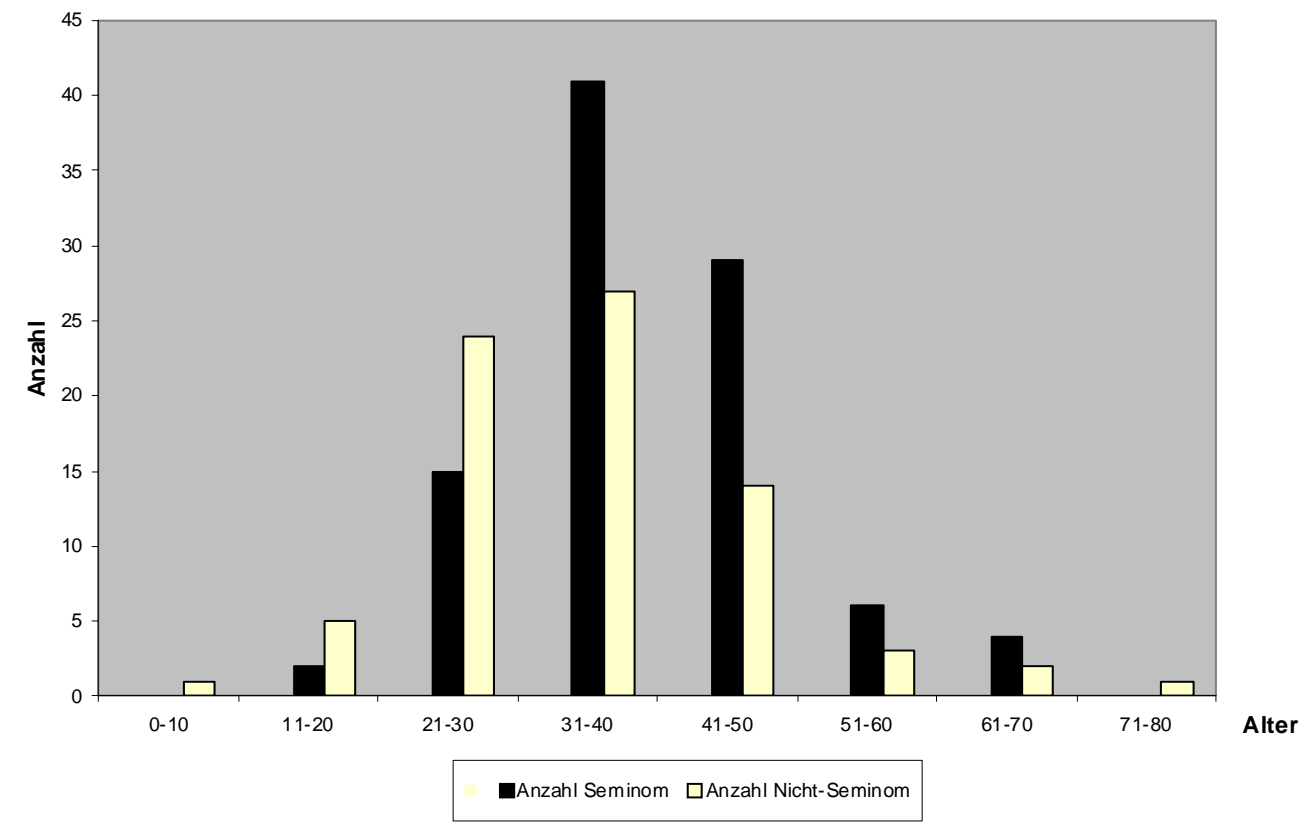

Abbildung 4: Altersverteilung des untersuchten Patientenkollektivs 
Die Auswertung der Tumorstadien der Patienten ergab, dass 71,3\% der Patienten ein Tumorstadium pT1, 20,1\% ein Tumorstadium pT2 und 2,9\% ein Tumorstadium pT3 aufwiesen. Des Weiteren war in 10 Fällen keine Angabe eines Tumorstadiums zu finden (Tabelle 9).

Tabelle 9: Tumorstadienverteilung des untersuchten Patientenkollektivs

\begin{tabular}{|lcc|}
\hline Tumorstadium & Anzahl & Prozent \\
\hline pT1 & 124 & 71,3 \\
pT2 & 35 & 20,1 \\
pT3 & 5 & 2,9 \\
keine Angabe & 10 & 5,7 \\
\hline
\end{tabular}

Die malignen Keimzelltumoren des Hodens waren in 54,5\% im rechten und in 44,3\% im linken Hoden lokalisiert. In einem Fall lag ein Bauchhoden ohne nähere Lokalisationsangabe vor und in einem weiteren Fall gab es keine Seitenangabe des Tumors (Tabelle 10).

Tabelle 10: Anatomische Lokalisation der malignen Keimzelltumoren des Hodens

\begin{tabular}{|lcc|}
\hline Lokalisation & Anzahl & Prozent \\
\hline rechts & 95 & 54,5 \\
links & 77 & 44,3 \\
Bauchhoden & 1 & 0,6 \\
keine Angabe & 1 & 0,6 \\
\hline
\end{tabular}

\subsection{Tumorentitäten}

Im untersuchten Patientenkollektiv der malignen Keimzelltumoren des Hodens fanden sich 96 reine Seminome und 3 spermatozytäre Seminome. In 75 Fällen wurde ein Nicht-Seminom diagnostiziert, wobei 15 embryonale Karzinome, ein Teratom und drei Dottersacktumoren vorlagen. Die restlichen 56 Fälle waren maligne Keimzelltumoren des Hodens aus mehr als einem histologischen Typ, sogenannte 
Mischtumoren, die sich aus seminomatösen und/oder nicht-seminomatösen Tumorkomponenten zusammensetzten (Tabelle 11).

Tabelle 11: Tumorentitäten des untersuchten Patientenkollektivs

\begin{tabular}{|llll|}
\hline Seminom & $\mathbf{9 9}$ & Nicht-Seminom & $\mathbf{7 5}$ \\
\hline Klassisches Seminom & 96 & Embryonales Karzinom & 15 \\
Spermatozytisches Seminom & 3 & Teratom & 1 \\
& & Dottersacktumor & 3 \\
& & Mischtumor & 56 \\
\hline
\end{tabular}

\subsection{Tissue-Microarrays}

Zur Herstellung der Tissue-Microarrays (TMAs) wurden bis zu 6 Paraffinblöcke mit Tumorgewebe pro Patient ausgewählt, aus denen zwischen 1 und 15 Stanzen entnommen wurden. Nach Abzug nicht auszuwertender Stanzen ergab sich eine Gesamtanzahl von 1032 Stanzen. Einer einzigen Stanze konnten teilweise mehrere Diagnosen zugeordnet werden. Als Diagnose wurden sowohl die einzelnen Tumorentitäten als auch IGCNU und Normalgewebe gewertet. Die daraus resultierende Diagnosenanzahl betrug 1314 und beinhaltete folgende Diagnosen ( $\mathrm{n}=$ Fälle):

Normalgewebe $(n=286)$, IGCNU ( $n=369)$, Seminom $(n=350)$, embryonales Karzinom $(n=170)$, Teratom $(n=91)$, Dottersacktumor $(n=23)$, Chorionkarzinom $(n=25)$.

Zusätzlich wurden im Rahmen der Auswertung weitere im Hodengewebe vorkommende Zellen und Veränderungen diagnostiziert $(n=111)$, die sich folgendermaßen aufteilten: Hodenfibrose $(n=57)$, Leydig-Zellen $(n=9)$, Sertoli-Zellen $(n=41)$, Sertoli-cell-only-Syndrom $(n=1)$, Spermatogenese-Arrest $(n=3)$. 


\subsection{Auswertung}

\subsubsection{Expression von Pan-CK in malignen Keimzelltumoren des Hodens}

Die immunhistochemischen Untersuchungen zur Expression von Pan-Zytokeratin in malignen Keimzelltumoren des Hodens ergaben, dass normales Hodengewebe in 98,6\% keine Expression zeigte $(n=286 ; 282 / 286)$, während die intratubuläre Keimzellneoplasie in 90,2\% ein positives Ergebnis präsentierte ( $n=369 ; 333 / 369)$. Im Gegensatz zu der nicht-invasiven Vorläuferläsion ließ sich bei Seminomen lediglich in 6\% eine Expression für Pan-Zytokeratin feststellen ( $n=350 ; 21 / 350)$. Die nichtseminomatösen Tumoren boten ein heterogenes Expressionsprofil für PanZytokeratin. Embryonale Karzinome reagierten in $92,9 \%$ positiv ( $n=170 ; 158 / 170)$, Teratome in etwa der Hälfte der Fälle ( $n=91 ; 54 / 91)$. Sowohl Dottersacktumoren $(n=23 ; 23 / 23)$ als auch Chorionkarzinome $(n=25 ; 25 / 25)$ zeigten durchweg ein positives Ergebnis (Abb. 5). Die Ergebnisse der Pan-Zytokeratin-Expression in malignen Keimzelltumoren des Hodens sind in Tabelle 12 zusammengefasst. 

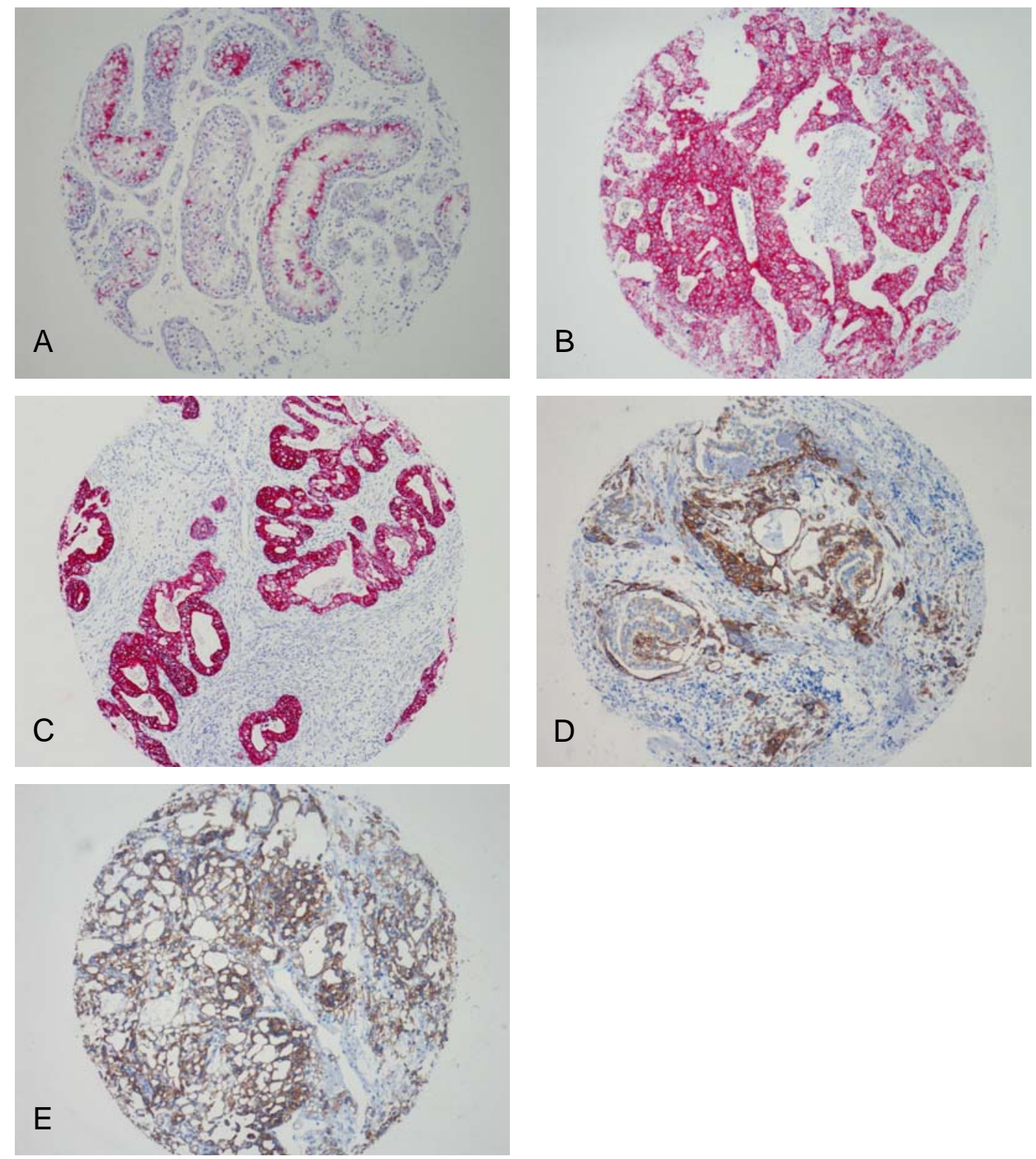

\section{Abbildung 5: Expression von Pan-CK in TGCT}

Die Expression von Pan-CK in TGCT wurde mittels Immunhistochemie untersucht. IGCNU (A; Vergrößerung, x100), embryonales Karzinom (B; Vergrößerung, x100), Teratom (C; Vergrößerung, x100), Chorionkarzinom (D; Vergrößerung, x100) und Dottersacktumor (E; Vergrößerung, $x 100)$ zeigen eine Expression von Pan-CK (rote/braune Signale). 


\subsubsection{Expression von PLAP in malignen Keimzelltumoren des Hodens}

Die immunhistochemischen Untersuchungen ergaben, dass PLAP in normalem Hodengewebe nicht nachweisbar ist ( $n=286$; 0/286), wohingegen die intratubuläre Keimzellneoplasie durchweg eine Expression der PLAP aufwies ( $n=369 ; 369 / 369)$. In ähnlich hohem Prozentsatz (96,5\%) ließ sich eine PLAP-Expression in Seminomen feststellen ( $n=350 ; 338 / 350)$. Im Gegensatz dazu zeigten die nicht-seminomatösen malignen Keimzelltumoren des Hodens ein heterogenes Expressionsmuster der PLAP, wobei die Mehrheit der Fälle keine Expression der PLAP aufwies. Embryonale Karzinome $(n=170)$ präsentierten ein divergentes Ergebnis: 56,5\% zeigten eine homogene $(6,5 \%, 11 / 170)$ oder fokale Expression $(50 \%, 85 / 170)$ der PLAP. In den übrigen 74 Fällen von embryonalen Karzinomen war keine Expression der PLAP nachweisbar (43,5\%). Bei den Teratomen konnte lediglich in 6,5\% der Fälle eine PLAP-Expression festgestellt werden ( $n=91,6 / 91)$. Sowohl in Dottersacktumoren $(n=23,0 / 23)$ als auch in Chorionkarzinomen $(n=25,0 / 25)$ ließ sich keine Expression der PLAP nachweisen (Abb. 6). Die Ergebnisse der PLAP-Expression in malignen Keimzelltumoren des Hodens sind in Tabelle 13 zusammengefasst.
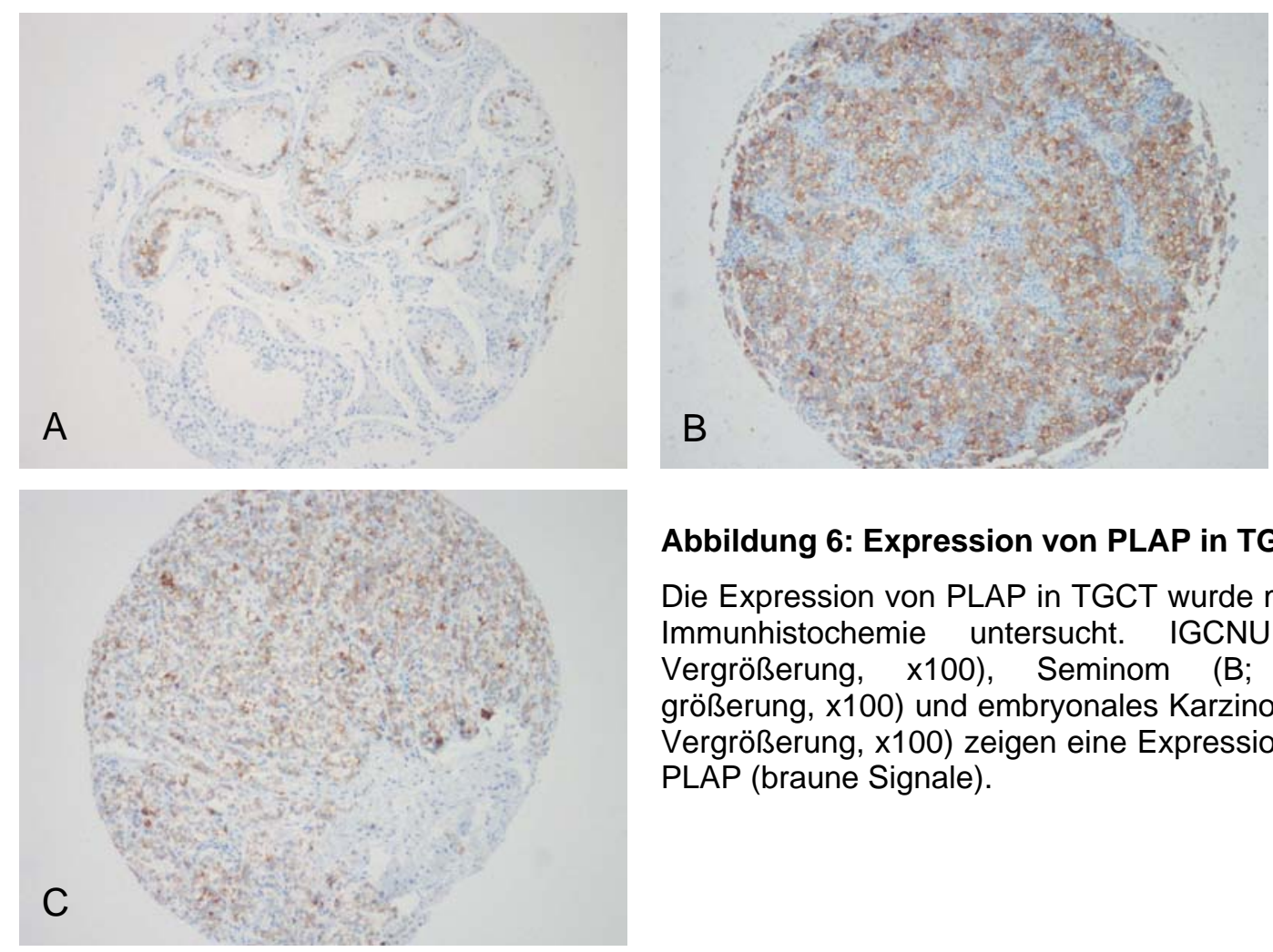

Abbildung 6: Expression von PLAP in TGCT

Die Expression von PLAP in TGCT wurde mittels Immunhistochemie untersucht. IGCNU (A; Vergrößerung, $\mathrm{x} 100)$, Seminom (B; Vergrößerung, $x 100)$ und embryonales Karzinom (C; Vergrößerung, x100) zeigen eine Expression von PLAP (braune Signale). 


\subsubsection{Expression von CD 30 in malignen Keimzelltumoren des Hodens}

Die immunhistochemischen Untersuchungen zur Expression von CD 30 in malignen Keimzelltumoren des Hodens zeigten sowohl für normales Hodengewebe $(n=286$; 0/286) als auch für die intratubuläre Neoplasie ( $n=369 ; 0 / 369)$ in 100\% ein negatives Ergebnis. Lediglich 0,9\% der Seminome zeigten eine meist fokale Expression für CD $30(n=350 ; 3 / 350)$. Die Expression von CD 30 in nicht-seminomatösen Tumoren präsentierte ein überwiegend negatives Ergebnis, als Ausnahme sind die embryonalen Karzinome zu nennen. In 94,1\% ließ sich eine Expression von CD 30 in den Tumorzellen feststellen ( $n=170 ; 160 / 170)$. Teratome $(n=91 ; 0 / 91)$, Dottersacktumoren $(n=23 ; 0 / 23)$ und Chorionkarzinome $(n=25 ; 0 / 25)$ zeigten keine Expression von CD 30 (Abb.7). Die immunhistochemischen Ergebnisse zur Expression von CD 30 in malignen Keimzelltumoren des Hodens sind in Tabelle 14 zusammengefasst.

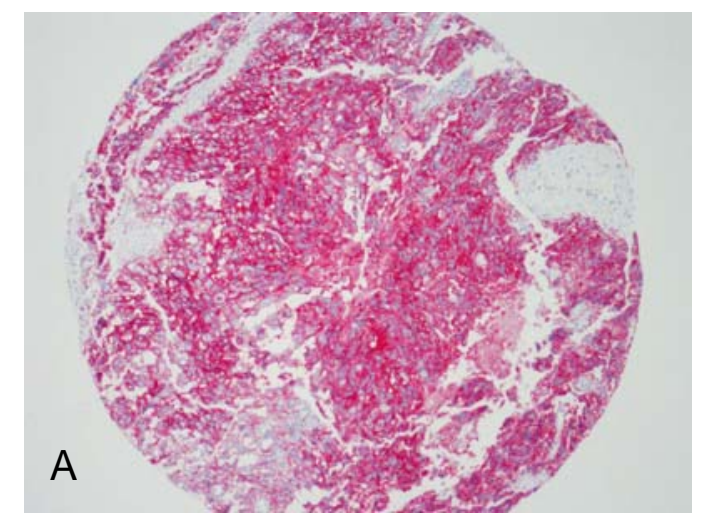

Abbildung 7: Expression von CD 30 in TGCT

Die Expression von CD 30 in TGCT wurde mittels Immunhistochemie untersucht. Embryonales Karzinom (A; Vergrößerung, x100) zeigt eine Expression von CD 30 (rotes Signal). 


\subsubsection{Expression von AFP in malignen Keimzelltumoren des Hodens}

Die immunhistologischen Untersuchungen zur Expression von AFP in malignen Keimzelltumoren des Hodens ergaben, dass normales Hodengewebe $(n=286$; 0/286), die testikuläre intratubuläre Keimzellneoplasie ( $n=369 ; 0 / 369)$ und das Seminom ( $n=350 ; 0 / 350)$ keine Expression von AFP aufwiesen. Im Gegensatz dazu präsentierten die nicht-seminomatösen malignen Keimzelltumoren des Hodens ein heterogenes Expressionsmuster von AFP, wobei die Mehrzahl der Fälle keine Expression von AFP zeigte. Embryonale Karzinome präsentierten in 97,6 \% keine Expression von AFP, lediglich 12\% der Teratome ließen eine schwache Expression von AFP erkennen $(n=91 ; 11 / 91)$. Alle untersuchten Chorionkarzinome zeigten keine Expression von AFP $(n=25 ; 0 / 25)$. Im Gegensatz dazu konnte in allen Dottersacktumoren eine Expression von AFP gezeigt werden ( $n=23 ; 23 / 23$ ) (Abb. 8). Die Ergebnisse der AFP-Expression in malignen Keimzelltumoren des Hodens sind in Tabelle 15 zusammengefasst.

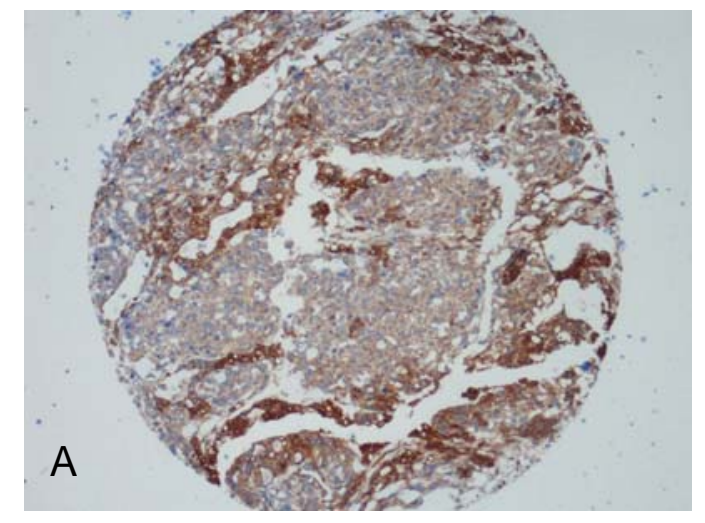

\section{Abbildung 8: Expression von AFP in TGCT}

Die Expression von AFP in TGCT wurde mittels Immunhistochemie untersucht.

Dottersacktumor (A; Vergrößerung, $x 100)$ zeigt eine Expression von AFP (braunes Signal). 


\subsubsection{Expression von ß-HCG in malignen Keimzelltumoren des Hodens}

Die immunhistochemischen Untersuchungen zur Expression von ß-HCG in malignen Keimzelltumoren des Hodens zeigten, dass sowohl normales Hodengewebe $(n=286$; 0/286) als auch die testikuläre intratubuläre Neoplasie $(n=369 ; 0 / 369)$ keine Expression von $\beta$-HCG aufwiesen. Ebenfalls zeigten Seminome ( $n=350 ; 0 / 350)$ als auch die nicht-seminomatösen Tumoren embryonales Karzinom ( $n=170 ; 0 / 170)$, Teratom $(n=91 ; 0 / 91)$ und Dottersacktumor $(n=23 ; 0 / 23)$ keine Expression von $ß-$ HCG. Im Gegensatz dazu konnte in nahezu allen untersuchten Chorionkarzinomen eine Expression von ß-HCG festgestellt werden $(n=25 ; 23 / 25)$ (Abb. 9). Die Ergebnisse der $\beta$-HCG-Expression in malignen Keimzelltumoren des Hodens sind in Tabelle 16 zusammengefasst.
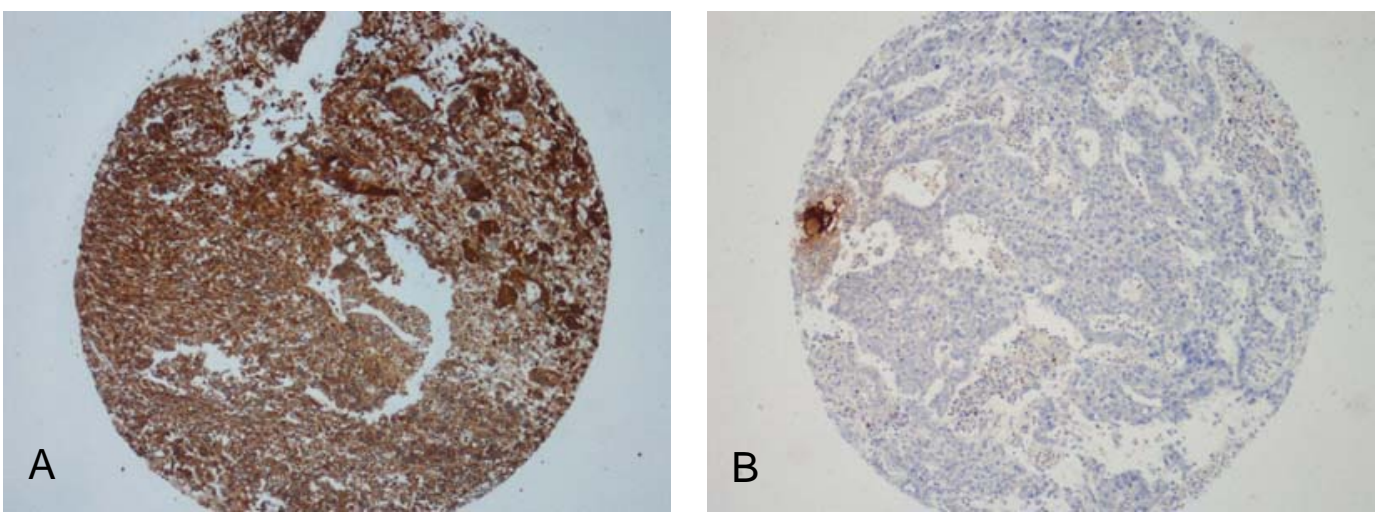

Abbildung 9: Expression von B-HCG in TGCT

Die Expression von B-HCG in TGCT wurde mittels Immunhistochemie untersucht.

Chorionkarzinom ( $A$; Vergrößerung, $x 100$ ) und Synzytiotrophoblast in einem embryonalen Karzinom (B; Vergrößerung, $x 100)$ zeigen eine Expression von ß-HCG (braune Signale). 


\subsubsection{Expression von Oct-3/4 in malignen Keimzelltumoren des Hodens}

Die immunhistochemischen Untersuchungen für Oct-3/4 in malignen Keimzelltumoren des Hodens demonstrierten für normales Hodengewebe ein durchweg negatives Ergebnis ( $n=286 ; 0 / 286)$. Im Gegensatz dazu zeigte die testikuläre intratubuläre Neoplasie in fast allen Fällen eine Expression für Oct-3/4 ( $n=369 ; 359 / 369$ ), ähnlich das Ergebnis der Seminome, in 96,6\% präsentierten diese eine Anfärbbarkeit ( $n=350 ; 338 / 350)$. Bei den nicht-seminomatösen Tumoren zeigte sich eine heterogene Expression für Oct-3/4. Während embryonale Karzinome zu 85,3\% eine Expression aufwiesen ( $n=170 ; 145 / 170)$, ließ sich bei den Teratomen nur in 2,2\% ein positives Ergebnis nachweisen $(n=91 ; 2 / 91)$. Sowohl bei den Dottersacktumoren $(n=23 ; 0 / 23)$ als auch bei den Chorionkarzinomen $(n=25 ; 0 / 25)$ konnte keine Expression von Oct-3/4 festgestellt werden (Abb.10). Die Ergebnisse der Oct-3/4-Expression in malignen Keimzelltumoren des Hodens sind in Tabelle 17 zusammengefasst.
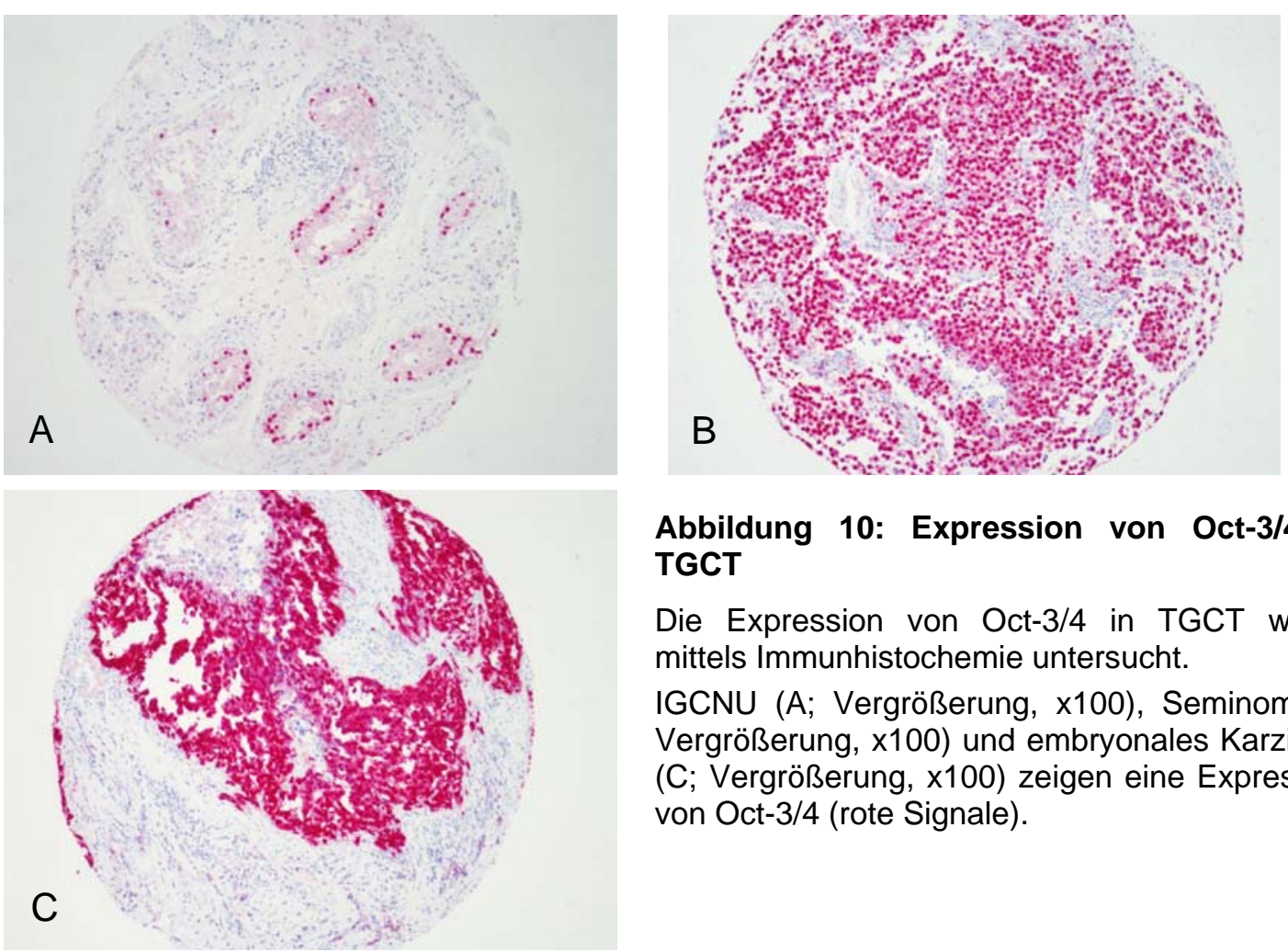

Abbildung 10: Expression von Oct-3/4 in TGCT

Die Expression von Oct-3/4 in TGCT wurde mittels Immunhistochemie untersucht.

IGCNU (A; Vergrößerung, x100), Seminom (B; Vergrößerung, $x 100)$ und embryonales Karzinom (C; Vergrößerung, $x 100)$ zeigen eine Expression von Oct-3/4 (rote Signale). 


\subsubsection{Expression von Sox2 in malignen Keimzelltumoren des Hodens}

Die immunhistochemischen Untersuchungen zur Expression von Sox2 in malignen Keimzelltumoren des Hodens ergaben, dass die Keimzellen des normalen Hodengewebes $(n=286 ; 0 / 286)$ sowie die intratubuläre Keimzellneoplasie keine Expression von Sox2 zeigten ( $n=369 ; 0 / 369)$. Die seminomatösen Tumoren zeigten ebenfalls keine Expression für Sox2 ( $n=350 ; 0 / 350)$. Die Expression von Sox2 in Nicht-Seminomen bot ein heterogenes Ergebnis. Die embryonalen Karzinome präsentierten in 98,8\% eine Expression von Sox2 ( $n=170 ; 168 / 170)$. Bei den Teratomen wurde in 29,7\% Sox2 detektiert, wobei im Wesentlichen die epitheliale Tumorkomponente Sox2 exprimierte $(n=91 ; 27 / 91)$. Sowohl die Dottersacktumoren $(n=23,0 / 23)$ als auch Chorionkarzinome $(n=25 ; 0 / 25)$ zeigten in keinem Fall eine Anfärbbarkeit für Sox2. Des Weiteren zeigten Sertoli-Zellen des normalen Hodengewebes eine Sox2-Expression (38/41) (Abb.11).

Die Ergebnisse der Sox2-Expression in malignen Keimzelltumoren des Hodens sind in Tabelle 18 zusammengefasst.
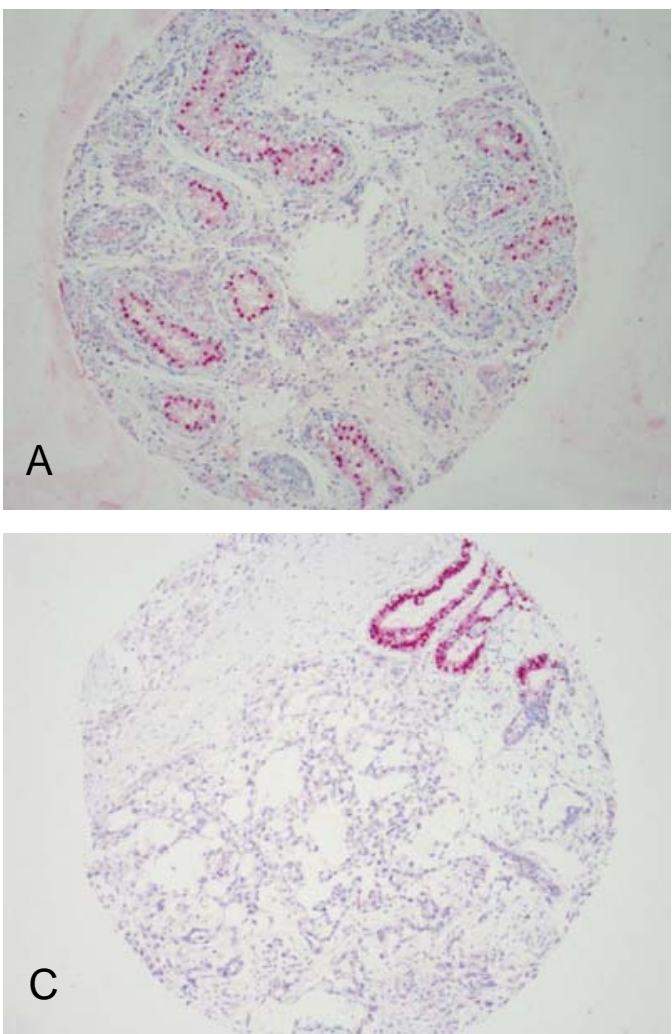

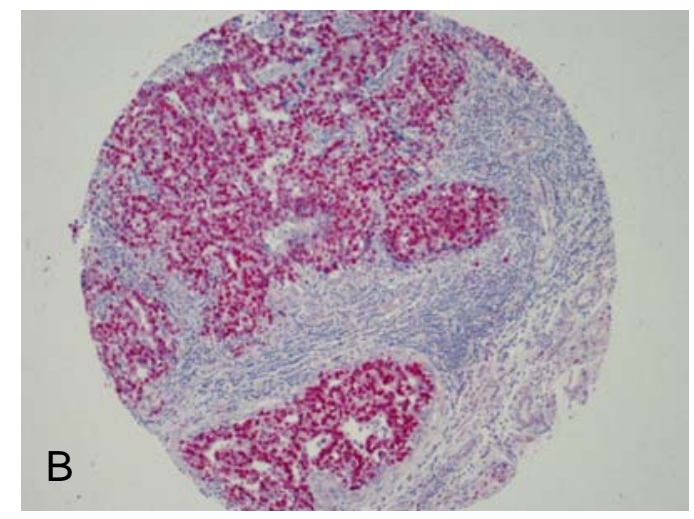

Abbildung 11: Expression von Sox2 in TGCT

Die Expression von Sox2 in TGCT wurde mittels Immunhistochemie untersucht.

Sertoli-Zellen in IGCNU (A; Vergrößerung, x100), embryonales Karzinom (B; Vergrößerung, x100) und epitheliale Tumorkomponente eines Teratoms (C; Vergrößerung, x100) zeigen eine Expression von Sox2 (rote Signale). 


\subsubsection{Expression von CD 117 in malignen Keimzelltumoren des Hodens}

Die immunhistochemischen Untersuchungen zur Expression von CD 117 in malignen Keimzelltumoren des Hodens zeigten für normales Hodengewebe in 99,7\% keine Expression ( $n=286 ; 1 / 286)$. Die intratubuläre Keimzellneoplasie präsentierte in 99,2\% eine Expression von CD 117 ( $n=369 ;$ 366/369). Ähnlich war das Ergebnis für die Seminome, die in 94,6\% eine Expression von CD 117 aufwiesen ( $n=350 ; 331 / 350)$. Die nicht-seminomatösen Tumoren zeigten in der Mehrzahl der Fälle keine Expression von CD 117. Lediglich 2,4\% der embryonalen Karzinome ( $n=170 ; 4 / 170)$ sowie 11\% der Teratome ( $n=91 ; 10 / 91)$ demonstrierten eine Expression von CD 117. Sowohl die Dottersacktumoren $(n=23 ; 0 / 23)$ als auch die Chorionkarzinome $(n=25$; 0/25) zeigten keine Expression von CD 117 (Abb.12). Eine Zusammenfassung der Ergebnisse für die Expression von CD 117 findet sich in Tabelle 19.
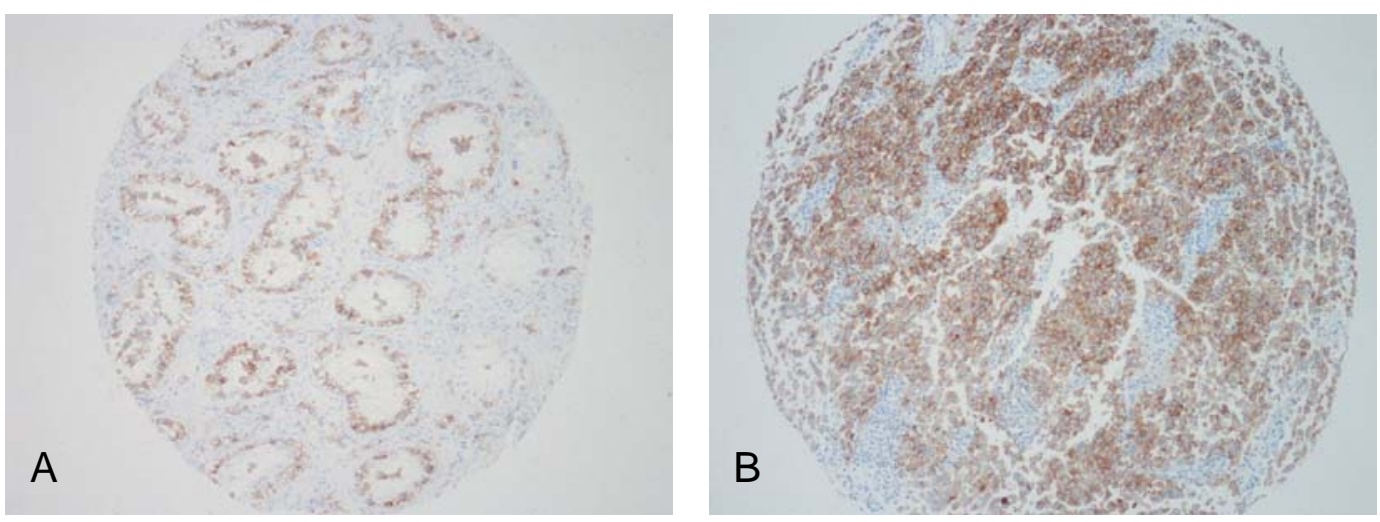

Abbildung 12: Expression von CD 117 in TGCT

Die Expression von CD 117 in TGCT wurde mittels Immunhistochemie untersucht. IGCNU (A; Vergrößerung, x100) und Seminom (B; Vergrößerung, x100) zeigen eine Expression von CD 117 (braune Signale). 


\subsubsection{Expression von D2-40 in malignen Keimzelltumoren des Hodens}

Die immunhistologischen Untersuchungen zur Expression von D2-40 in malignen Keimzelltumoren ergaben, dass normales Hodengewebe keine Expression von D240 zeigte $(n=286 ; 0 / 286)$. Die testikuläre intratubuläre Keimzellneoplasie $(n=369$; $369 / 369)$ als auch die Seminome $(n=350 ; 350 / 350)$ präsentierten in $100 \%$ eine Expression von D2-40. Die nicht-seminomatösen Tumoren zeigten in Einzelfällen ein positives Ergebnis, während die Mehrheit der Tumoren keine Expression aufwies. Lediglich 6,5\% der embryonalen Karzinome zeigten ein positives Ergebnis für D2-40 $(n=170 ; 11 / 170)$, bei den Teratomen wiesen nur 3,4\% eine Expression auf $(n=91$; 3/91). Sowohl Dottersacktumoren $(n=23 ; 0 / 23)$ wie auch Chorionkarzinome (=25; 0/25) zeigten keine Expression von D2-40 (Abb. 13). Die Ergebnisse der immunhistologischen Untersuchungen von D2-40 sind in Tabelle 20 zusammengefasst.
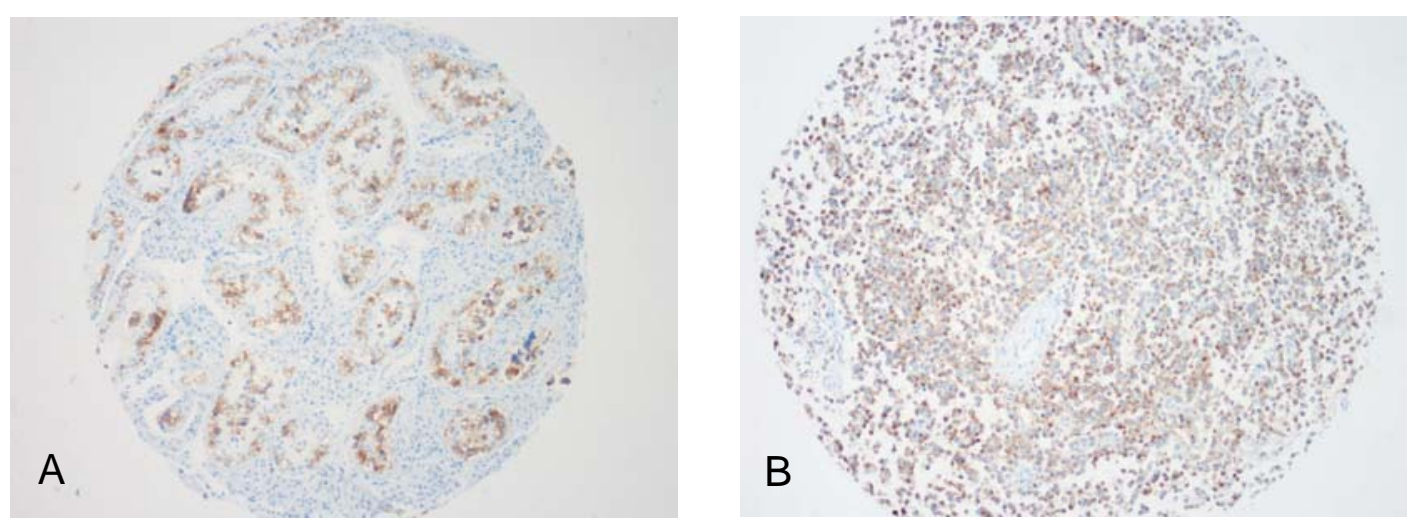

Abbildung 13: Expression von D2-40 in TGCT

Die Expression von D2-40 in TGCT wurde mittels Immunhistochemie untersucht. IGCNU (A; Vergrößerung, x100) und Seminom (B; Vergrößerung, x100) zeigen eine Expression von D2-40 (braune Signale). 


\subsubsection{Expression von CD 9 in malignen Keimzelltumoren des Hodens}

Die immunhistochemischen Untersuchungen für CD 9 in malignen Keimzelltumoren des Hodens zeigten für normales Hodengewebe keine Expression ( $n=286 ; 0 / 286)$.

Sowohl die intratubuläre Keimzellneoplasie $(n=369 ; 369 / 369)$ als auch Seminome $(n=350 ; 350 / 350)$ präsentierten in $100 \%$ ein positives Ergebnis. Die nichtseminomatösen Tumoren zeigten ein heterogenes Bild. Während embryonale Karzinome in allen Fällen eine Expression für CD 9 aufwiesen ( $n=170 ; 170 / 170)$, konnte bei den Teratomen in $83,5 \%$ eine Anfärbbarkeit festgestellt werden $(n=91$; 76/91). Dottersacktumoren zeigten keine Expression für CD 9 ( $n=23 ; 0 / 23)$. Im Gegensatz dazu ließ sich bei den Chorionkarzinomen in 32\% der Fälle ein positives Ergebnis nachweisen, in einem der Fälle zeigte sich ein fokal positives Ergebnis $(n=25 ;$ 8/25) (Abb.14). Die Ergebnisse für die immunhistochemischen Untersuchungen für CD 9 sind in Tabelle 21 zusammengefasst.
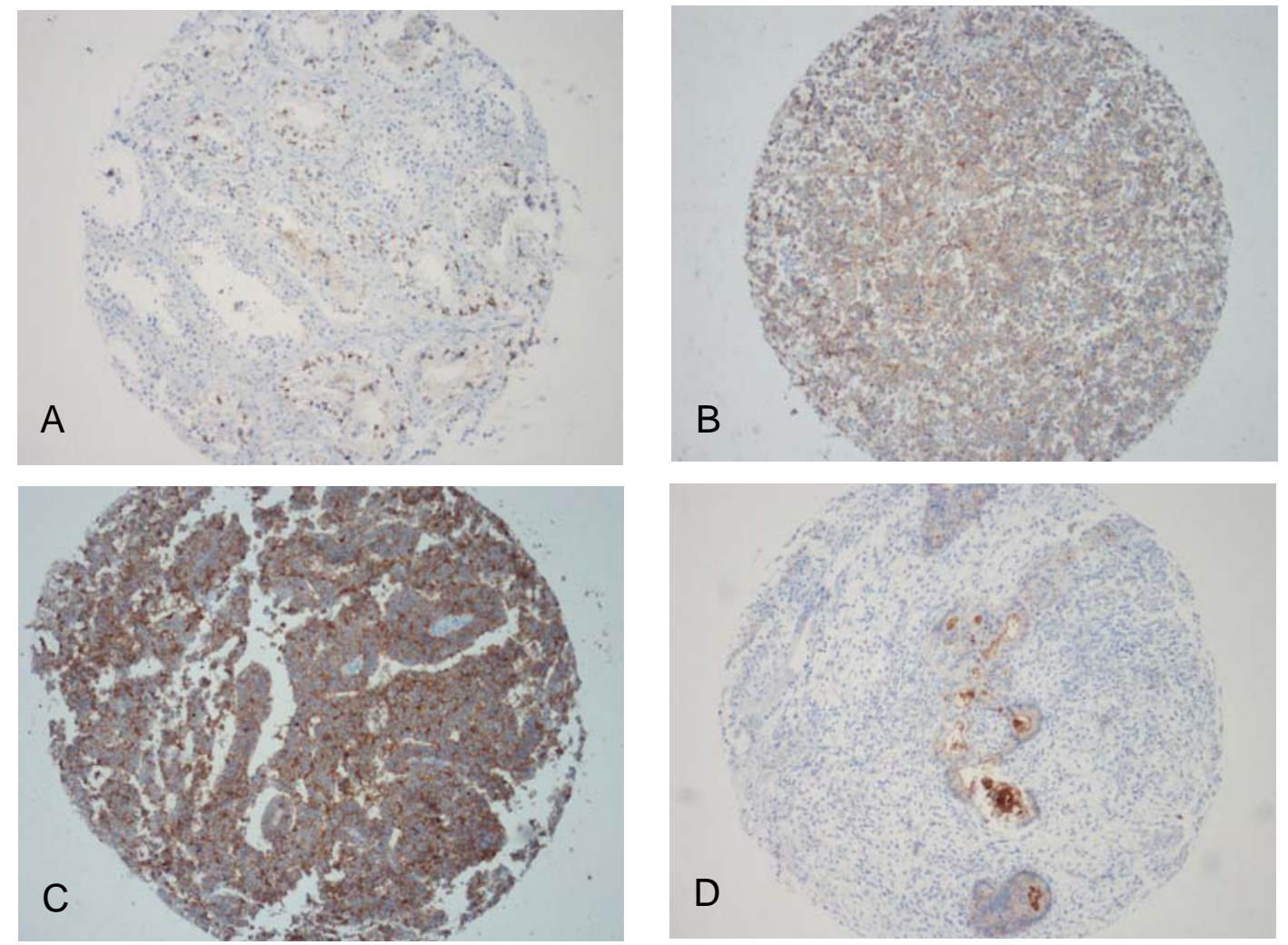

Abbildung 14: Expression von CD 9 in TGCT

Die Expression von CD 9 in TGCT wurde mittels Immunhistochemie untersucht. IGCNU (A; Vergrößerung, x100), Seminom (B; Vergrößerung, x100), embryonales Karzinom (C; Vergrößerung, x100) und Teratom (D; Vergrößerung, x100) zeigen eine Expression von CD 9 (braune Signale). 


\subsection{Tabellarische Übersicht der Ergebnisse}

Tabelle 12: Expression von Pan-CK in TGCT

\begin{tabular}{|l|l|l|l|}
\hline & $\mathbf{n}$ & positiv & $\%$ \\
\hline Normal & 286 & 4 & 1,4 \\
\hline IGCNU & 369 & 333 & 90,2 \\
\hline SE & 350 & 21 & 6 \\
\hline EC & 170 & 158 & 92,9 \\
\hline TE & 91 & 54 & 59,3 \\
\hline DST & 23 & 23 & 100 \\
\hline CC & 25 & 25 & 100 \\
\hline
\end{tabular}
13. Expression vo PLAP in TGCT

\begin{tabular}{|l|l|l|l|}
\hline & $\mathbf{n}$ & positiv & $\%$ \\
\hline Normal & 286 & 0 & 0 \\
\hline IGCNU & 369 & 369 & 100 \\
\hline SE & 350 & 338 & 96,5 \\
\hline EC & 170 & 96 & 56,5 \\
\hline TE & 91 & 6 & 6,5 \\
\hline DST & 23 & 0 & 0 \\
\hline CC & 25 & 0 & 0 \\
\hline
\end{tabular}

Tabelle 17: Expression von Oct-3/4 in TGCT

\begin{tabular}{|l|l|l|l|}
\hline & $\mathbf{n}$ & positiv & $\%$ \\
\hline Normal & 286 & 0 & 0 \\
\hline IGCNU & 369 & 359 & 97,3 \\
\hline SE & 350 & 338 & 96,6 \\
\hline EC & 170 & 145 & 85,3 \\
\hline TE & 91 & 2 & 2,2 \\
\hline DST & 23 & 0 & 0 \\
\hline CC & 25 & 0 & 0 \\
\hline
\end{tabular}

Tabelle 18: Expression von Sox2 in TGCT

\begin{tabular}{|l|l|l|l|}
\hline & $\mathbf{n}$ & positiv & $\%$ \\
\hline Normal & 286 & 0 & 0 \\
\hline IGCNU & 369 & 0 & 0 \\
\hline SE & 350 & 0 & 0 \\
\hline EC & 170 & 168 & 98,8 \\
\hline TE & 91 & 27 & 29,7 \\
\hline DST & 23 & 0 & 0 \\
\hline CC & 25 & 0 & 0 \\
\hline
\end{tabular}

Tabelle 14: Expression von CD 30 in TGCT

\begin{tabular}{|l|l|l|l|}
\hline & $\mathbf{n}$ & positiv & $\%$ \\
\hline Normal & 286 & 0 & 0 \\
\hline IGCNU & 369 & 0 & 0 \\
\hline SE & 350 & 3 & 0,9 \\
\hline EC & 170 & 160 & 94,1 \\
\hline TE & 91 & 0 & 0 \\
\hline DST & 23 & 0 & 0 \\
\hline CC & 25 & 0 & 0 \\
\hline
\end{tabular}

abelle 19: Expression von CD 117 in TGCT

\begin{tabular}{|l|l|l|l|}
\hline & $\mathbf{n}$ & positiv & $\%$ \\
\hline Normal & 286 & 1 & 0,3 \\
\hline IGCNU & 369 & 366 & 99,2 \\
\hline SE & 350 & 331 & 94,6 \\
\hline EC & 170 & 4 & 2,4 \\
\hline TE & 91 & 10 & 11 \\
\hline DST & 23 & 0 & 0 \\
\hline CC & 25 & 0 & 0 \\
\hline
\end{tabular}

Tabelle 15: Expression von AFP in TGCT

\begin{tabular}{|l|l|l|l|}
\hline & $\mathbf{n}$ & positiv & $\%$ \\
\hline Normal & 286 & 0 & 0 \\
\hline IGCNU & 369 & 0 & 0 \\
\hline SE & 350 & 0 & 0 \\
\hline EC & 170 & 4 & 2,4 \\
\hline TE & 91 & 11 & 12 \\
\hline DST & 23 & 23 & 100 \\
\hline CC & 25 & 0 & 0 \\
\hline
\end{tabular}

Tabelle 20: Expression von D2-40 in TGCT

\begin{tabular}{|l|l|l|l|}
\hline & $\mathbf{n}$ & positiv & $\%$ \\
\hline Normal & 286 & 0 & 0 \\
\hline IGCNU & 369 & 369 & 100 \\
\hline SE & 350 & 350 & 100 \\
\hline EC & 170 & 11 & 6,5 \\
\hline TE & 91 & 3 & 3,4 \\
\hline DST & 23 & 0 & 0 \\
\hline CC & 25 & 0 & 0 \\
\hline
\end{tabular}

Tabelle 16: Expression von B-HCG in TGCT

\begin{tabular}{|l|l|l|l|}
\hline & $\mathbf{n}$ & positiv & $\%$ \\
\hline Normal & 286 & 0 & 0 \\
\hline IGCNU & 369 & 0 & 0 \\
\hline SE & 350 & 0 & 0 \\
\hline EC & 170 & 0 & 0 \\
\hline TE & 91 & 0 & 0 \\
\hline DST & 23 & 0 & 0 \\
\hline CC & 25 & 23 & 92 \\
\hline
\end{tabular}

Tabelle 21: Expression von CD 9 in TGCT

\begin{tabular}{|l|l|l|l|}
\hline & $\mathbf{n}$ & positiv & $\%$ \\
\hline Normal & 286 & 0 & 0 \\
\hline IGCNU & 369 & 369 & 100 \\
\hline SE & 350 & 350 & 100 \\
\hline EC & 170 & 170 & 100 \\
\hline TE & 91 & 76 & 83,5 \\
\hline DST & 23 & 0 & 0 \\
\hline CC & 25 & 8 & 32 \\
\hline
\end{tabular}




\section{Diskussion}

\subsection{Patientenkollektiv und histopathologische Einteilung}

Maligne Keimzelltumoren des Hodens repräsentieren den häufigsten malignen soliden Tumor des jungen Mannes zwischen dem 20. und 40. Lebensjahr, wobei die Nicht-Seminome im Durchschnitt etwa 10 Jahre früher als Seminome auftreten (Ekbom and Akre 1998). Das in der vorliegenden Arbeit untersuchte Patientenkollektiv hatte ein Durchschnittsalter von 36,8 Jahren. Nicht-Seminome zeigten dabei ebenfalls ein jüngeres Erkrankungsalter mit 34,7 Jahren im Vergleich zu 38,6 Jahren bei den Seminomen. Somit liegen die ermittelten Erkrankungsalter bei Seminomen und Nicht-Seminomen in der Tendenz zu bereits publizierten epidemiologischen Studien, wobei lediglich eine Differenz von 4 Jahren festzustellen war (Holzik et al. 2008; Looijenga and Oosterhuis 1999). Dies könnte darauf zurückzuführen sein, dass vereinzelte Fälle von Nicht-Seminomen aus vorangegangen Jahrgängen hinzugefügt wurden, aber kein gesamtes Kollektiv daraus betrachtet wurde.

Bei der Lokalisation der untersuchten TGCT fiel auf, dass die Verteilung eine leichte Tendenz zu Gunsten des rechten Hodens aufwies (rechts: 54,5\%, links: 44,3\%). Dieses Ergebnis ist in Übereinstimmung mit publizierten Daten von Stone et al. aus dem Jahr 1991 und wird eventuell auf einen späteren Descensus des rechten Hodens zurückgeführt (Stone et al. 1991).

Die Verteilung der histologischen Entitäten dieser Arbeit ähnelte der in der Literatur beschriebenen. Reine Seminome machten mit 56,9\% einen Großteil der TGCT aus, Nicht-Seminome, zu denen auch die Mischtumoren gezählt wurden, dementsprechend 43,1\%. Reine embryonale Karzinome stellten mit 8,6\% den größten Teil dieser nicht-seminomatösen Tumoren dar, gefolgt von reinen Dottersacktumoren mit $1,7 \%$ und reinen Teratomen mit 0,6\%. In 32,2\% lag ein Mischtumor vor. Im Regelfall treten reine Teratome häufiger auf als reine Dottersacktumoren. Da in dieser Arbeit aber kein Unterschied zwischen reinen Tumoren und Mischtumoren hinsichtlich der Auswertung der einzelnen Gewebezylinder gemacht wurde, liegt hier eine Diskrepanz vor (Ulbright 2005). 


\subsection{Immunhistochemisches Expressionsprofil von TGCT}

Immunhistochemische Untersuchungen von TGCT dienen einerseits dazu, die unterschiedlichen histologischen Entitäten eines TGCT zu bestimmen und somit die Therapie und Prognose der Tumoren festzulegen. Zum Anderen hilft die Immunhistochemie von TGCT, die Genese der testikulären Keimzelltumoren besser zu verstehen. Im Hinblick auf die Genese der malignen Keimzelltumoren des Hodens wird postuliert, dass sich die maligne Transformation der primordialen Keimzellen bereits intrauterin manifestiert, wobei der genaue Ablauf der Karzinogenese der TGCT unklar ist.

Pan-CK ist ein wasserunlösliches Polypeptid mit einem Gewicht zwischen 40 und 70 kDa und zählt neben Vimentin, Desmin und den Neuro- bzw. Gliafilamenten zu den Intermediärfilamenten (Battifora et al. 1984; Miettinen et al. 1985). Pan-CK steht mit anderen Intermediärfilamenten in Verbindung und trägt zur Erhaltung der Zellstruktur innerhalb des Zytoskeletts bei (Miettinen et al. 1984). Pan-CK wird in nahezu allen Zellen epithelialen Ursprungs exprimiert und lässt sich somit in allen malignen epithelialen Tumoren nachweisen (Battifora et al. 1984; Miettinen et al. 1984). Im normalen Hoden zeigt lediglich die Rete testis eine Expression von Pan-CK, wohingegen die Keimzellen sowie die Zellen des Keimstrang-Stromas des Hodens Pan-CK nicht aufweisen (Miettinen et al. 1985).

In der vorliegenden Arbeit zeigten alle histologischen Entitäten der TGCT eine wenn auch nur vereinzelte Expression von Pan-CK. Normales Hodengewebe zeigte in 4 von 286 Fällen eine positive Reaktion im Bereich von miterfassten Rete-TestisAnteilen. Die IGCNU ließ in 90,2\% eine Pan-CK-Expression erkennen, wohingegen nur 21 der 350 untersuchten Seminome für anti-Pan-CK positiv reagierten. Bei den Nicht-Seminomen ließ sich Pan-CK in allen Dottersacktumoren und Chorionkarzinomen sowie in 92,9\% der embryonalen Karzinome nachweisen. Auch die epitheliale Tumorkomponente der Teratome präsentierte im Gegensatz zum mesenchymalen Tumoranteil eine Expression von Pan-CK, so dass lediglich in etwa der Hälfte der Fälle eine Pan-CK-Expression vorlag.

Miettinen et al. beschrieben 1985 in normalem Hodengewebe eine Pan-CK-positive Zellpopulation, bei der es sich retrospektiv in erster Linie um Anteile der Rete testis 
handeln dürfte (Miettinen et al. 1985). Diese Ergebnisse sind in Übereinstimmung mit unserer Beobachtung, dass lediglich die Rete testis in normalem Hodengwebe eine Expression von Pan-CK aufweist. Ebenfalls beschrieben Miettinen et al. 1985 atrophe Tubuli seminiferi, die in der Regel eine verdickte Basalmembran aufwiesen, als Pan-CK-positiv, was mit dem Erscheinungsbild von IGCNU übereinstimmt und somit als Pan-CK-Expression von atypischen Keimzellen der IGCNU zu werten ist. Diese Ergebnisse sind weitgehend in Übereinstimmung mit der in dieser Arbeit beobachteten Expression von Pan-CK in ca. 90\% der IGCNU. Bei der Betrachtung der Pan-CK-Expression in Seminomen, die in der vorliegenden Dissertationsschrift bei $6 \%$ lag, fällt auf, dass für diese Tumorentität sehr heterogene Expressionsprofile beschrieben sind. Fogel et al. (1990) werteten 19 von 26 Seminomen als positiv, wohingegen andere Arbeitsgruppen eine deutlich geringere Anzahl von Pan-CKexprimierenden Seminomen beschrieben haben (Eglen and Ulbright 1987; Miettinen et al. 1985). Noch signifikanter sind die Ergebnisse von Battifora et al. zu werten, die in 41 untersuchten Seminomen keine Expression von Pan-CK feststellen konnten (Battifora et al. 1984). Interessanterweise beschrieben Cheville et al., dass sich die Prognose von Seminomen mit Pan-CK-Expression im Vergleich zu Pan-CKnegativen Seminomen nicht unterscheidet (Cheville et al. 2000). Somit kann eine eindeutige Aussage zur Expression von Pan-CK in Seminomen nicht getroffen werden. Dennoch kann in Zusammenschau der publizierten Daten und unserer Beobachtung von weniger als $10 \%$ Pan-CK-exprimierender Seminome ausgegangen werden.

In den genannten Publikationen zur Pan-CK-Expression in Seminomen zeigten in Analogie zu unseren Ergebnissen alle nicht-seminomatösen Tumoren eine Pan-CKExpression, wobei bei den Teratomen lediglich der epitheliale Tumoranteil positiv reagierte.

PLAP war einer der ersten immunhistochemischen Marker, der in Verbindung mit TGCT untersucht wurde. Bereits 1953 beschrieben McKay et al. Keimzellen, die sich mit einer alkalischen Phosphatase anfärben ließen (McKay et al. 1953). Die alkalische Phosphatase stellt ein membrangebundenes Glykoprotein dar, von dem mehrere Untereinheiten bekannt sind, unter anderem die von der Plazenta produzierte (Wick et al. 1987). Während der Wanderung vom Dottersack zu den Gonadalleisten wird die PLAP physiologischerweise von primordialen Keimzellen bis 
zum 15.-16. Tag post conceptionem exprimiert. Darüberhinaus zeigen Synzytiotrophoblasten der Plazenta ab der 8. SSW eine Expression der PLAP (Millán and Fishman 1995).

IGCNU und Seminome zeigten in dieser Arbeit eine Expression der PLAP, während Dottersacktumoren, Chorionkarzinome und normales Hodengewebe keinerlei Expression präsentierten. Embryonale Karzinome waren in der Hälfte der Fälle positiv und 6 der 91 Teratome zeigten ebenfalls eine Expression.

Viele Studien beschäftigten sich mit der Expression von PLAP in TGCT. 1988 führten Burke and Mostofi eine Studie zur PLAP-Expression in TGCT mit einem verhältnismäßig großen Patientenkollektiv durch. In deren Studie waren ebenfalls 78 von 81 Seminomen und 154 von 155 Fällen IGCNU positiv, allerdings zeigten auch ein Großteil der embryonalen Karzinome, nämlich 87 der 91 untersuchten Fälle, eine Expression für PLAP. Zusätzlich konnten sie zwischen reinen Tumoren und solchen, die in Mischtumoren vorkommen, keinen Unterschied finden. Allerdings beschrieben sie auch für 5 der 11 Chorionkarzinome sowie 14 der 56 Dottersacktumoren eine Expression für PLAP, was in der vorliegenden Arbeit nicht reproduziert werden konnte. Ebenfalls beschrieben Burke und Mostofi für eine sehr geringe Anzahl von Teratomen (6 von 116 Fällen) eine schwache Expression der PLAP (Burke and Mostofi 1988). Auch andere Autoren wie Beckstead oder Wick et al. beschrieben für embryonale Karzinome in allen Fällen ein positives Ergebnis, allerdings bezogen auf Patientenkollektive, die nur 14 bzw. 11 Fälle beinhalteten (Beckstead 1983; Wick et al. 1987). Die Diskrepanz, insbesondere was die PLAP-Expression in nichtseminomatösen Tumoren betrifft, ist möglicherweise auf den Einsatz unterschiedlicher Antikörper (polyklonale versus monoklonale Antikörper) bzw. die Anwendung verschiedener Färbeprotokolle zurückzuführen.

CD 30 gehört als Oberflächenrezeptor mit einem Molekulargewicht von 120 kDa zur Familie der Tumor-Nekrose-Faktoren und spielt eine wesentliche Rolle bei der Proliferation, Differenzierung und Apoptose von lymphoiden Zellen (Hittmair et al. 1996; Smith et al. 1993). 1982 wurde CD 30 erstmals als diagnostischer Marker der Reed-Sternberg-Zellen und Hodgkin-Zellen in Hodgkin-Lymphomen beschrieben (Schwab et al. 1982). Auch andere lymphatische Systemerkrankungen wie das anaplastische T-Zell-Lymphom oder das primär mediastinale B-Zell-Lymphom zeigen 
eine Expression von CD 30. Der einzige nicht-hämatopoetische Tumor, der eine Expression von CD 30 zeigt, ist das embryonale Karzinom (Hittmair et al. 1996). In dieser Arbeit präsentierten nahezu alle untersuchten embryonalen Karzinome sowie 3 von 350 Seminomen eine Expression von CD 30, während alle IGCNU und weitere TGCT-Entitäten ein negatives Ergebnis zeigten. Was die Expression von CD 30 in embryonalen Karzinomen sowie die fehlende Expression von CD 30 in allen anderen TGCT-Entitäten betrifft, sind die Ergebnisse der vorliegenden Arbeit in Übereinstimmung mit den publizierten Daten von Lau et al. (2007) und Gopalan et al. (2009). Diese konnten in ihren untersuchten Patientenkollektiven eine ähnlich hohe Anzahl von CD-30-positiven embryonalen Karzinomen feststellen. Die Spezifität von $C D 30$ für embryonale Karzinome wird gemindert durch einige positiv reagierende Seminome, die sowohl hier als auch bei Hittmaier et al. (11/35) und Leroy et al. (2/32) beschrieben wurden. Andere Arbeitsgruppen konnten die Expression von CD 30 in Seminomen nicht reproduzieren (Gopalan et al. 2009; Lau et al. 2007). Hittmaier et al. äußerten die Vermutung, dass sich die CD-30-positiven Seminome in der Weiterentwicklung zu einem embryonalen Karzinom befinden könnten, was die Hypothese bestätigen würde, dass sich diese aus Seminomen entwickeln. Leroy et al. widmeten eine Studie der Unterscheidung von embryonalen Karzinomen und Seminomen anhand der Marker CD 30 und CD 117, in der sie eine Kombination dieser beiden Marker für die Differenzierung vorschlugen. Demnach ist eine Kombination von CD-30-Negativität und CD-117-Positivität ein Hinweis auf ein Seminom bzw. spricht eine CD-30-Positivität und eine CD-117-Negativität für ein embryonales Karzinom (Leroy et al. 2002).

AFP ist ein Glykoprotein mit $70 \mathrm{kDa}$, das von dem fötalen Dottersack sowie der Leber und dem Gastrointestinaltrakt produziert wird (de Matteis and Silverio 1987). Während der Schwangerschaft ist ein positiver Serumwert messbar und auch bei Lebererkrankungen und TGCT ist ein pathologischer AFP-Wert im Serum festzustellen (Schefer et al. 2003). Bereits in den späten 60er Jahren des 20. Jahrhunderts fanden Beschreibungen von erhöhten AFP-Werten bei Patienten mit malignen Keimzelltumoren statt, woraufhin Anfang der 70er Jahre dann verstärkt Untersuchungen zur Identifikation des malignen Keimzelltumors und der Assoziation von Dottersacktumoren mit AFP durchgeführt wurden (Beilby et al. 1979). 
Ergebnisse dieser Arbeit zeigten eine AFP-Expression in 100\% der 23 untersuchten Dottersacktumoren. Ebenfalls zeigten 4 der 170 embryonalen Karzinome und 11 der 91 Teratome eine Expression von AFP. Alle IGCNU als auch weitere TGCT-Entitäten zeigten keine AFP-Expression.

Dottersacktumoren zeigten in der vorliegenden Arbeit in 100\% eine AFP-Expression. Diese Ergebnisse sind in Kontrast zu den publizierten Daten von Eglen und Ulbright, die bei 20 untersuchten Dottersacktumoren lediglich 11 Fälle mit AFP-Expression feststellen konnten (Eglen and Ulbright 1987). Niehans et al. führten 1988 eine Studie durch, in der sie für $75 \%$ der Dottersacktumoren eine Expression von AFP nachweisen konnten. Morinaga et al. wiederum beschrieben in 100\% der Fälle (5 von 5) eine positive Expression in Dottersacktumoren (Morinaga et al. 1983). Zusammenfassend stellten Emerson und Ulbright fest, dass eine positive AFPExpression zur Unterscheidung von Seminomen und Dottersacktumoren dienlich sei, eine fehlende AFP-Expression allerdings keine große Aussagekraft in der Differentialdiagnostik habe (Emerson and Ulbright 2005). In den zitierten Arbeiten zur Expression von AFP in Dottersacktumoren konnte in embryonalen Karzinomen in unterschiedlichem Prozentsatz ebenfalls eine AFP-Expression nachgewiesen werden. Talerman deutete die AFP-exprimierenden Zellen in embryonalen Karzinomen vom morphologischen und funktionellen Standpunkt her gesehen als Zellen des embryonalen Karzinoms mit Dottersackdifferenzierung (Talerman 1980). Weiterhin wurden muköse Drüsen bzw. leberähnliche Zellen in Teratomen beschrieben, die AFP exprimierten (de Matteis and Silverio 1987; Morinaga et al. 1983; Niehans et al. 1988). Somit kann postuliert werden, dass neben den Dottersacktumoren embryonale Karzinome und Teratome fokal eine AFP-Expression zeigen können, wohingegen die Diagnose eines Seminoms die Expression von AFP ausschließt.

ß-HCG stellt die ß-Untereinheit eines Glykoproteins mit einem Molekulargewicht von $38 \mathrm{kDa}$ dar, das von Synzytiotrophoblasten der Plazenta produziert wird (de Matteis and Silverio 1987). Darüberhinaus ist bekannt, dass Synzytiotrophoblasten eines Chorionkarzinoms ß-HCG synthetisieren, welches dann als Tumormarker im Serum erkrankter Patienten nachweisbar ist (Morinaga et al. 1983). 
In der vorliegenden Dissertation zeigten 23 von 25 (92\%) untersuchten Chorionkarzinomen eine ß-HCG-Expression, während alle anderen TGCT-Entitäten keine Expression aufwiesen.

Im Gegensatz dazu beschrieben Morinaga et al. zusätzlich zu den Chorionkarzinomen auch eine ß-HCG-Expression in einzelnen Tumorzellen von Seminomen sowie embryonalen Karzinomen. Obwohl bekannt ist, dass Synzytiotrophoblasten B-HCG produzieren, wiesen die Autoren aber daraufhin, dass mononukleäre Zellen die Anfärbbarkeit präsentierten und nicht die synzytiotrophoblastären Zellen und stellten daraufhin in Frage, ob ß-HCG produzierende Zellen synzytiale Strukturen beinhalten müssen. Ähnliche Ergebnisse präsentierten Niehans et al. 1988 in einer groß angelegten Studie, in der sie eine ßHCG-Expression für 3 von 43 Seminomen und 12 von 50 embryonalen Karzinomen beschrieben, ebenso ein 100\%-positives Ergebnis für 11 Chorionkarzinome (Niehans et al. 1988). Weissbach et al. widmeten ihre Studie der Frage, ob ß-HCG-positive Seminome eine schlechtere Prognose bzw. eine alternative Therapie benötigen, konnten aber keinen signifikanten Unterschied zu den ß-HCG-negativen Seminomen feststellen (Weissbach et al. 1999). Zusammenfassend kann postuliert werden, dass Chorionkarzinome typischerweise eine Expression von ß-HCG zeigen und alle anderen histologischen Entitäten der TGCT ß-HCG nicht exprimieren. Ausnahme hiervon sind Seminome mit synzytiotrophoblastären Zellen, die von der WHO als Sonderform eines Seminoms klassifiziert werden.

Oct-3/4 ist ein Transkriptionsfaktor in pluripotenten embryonalen Stammzellen. Zusammen mit dem Transkriptionsfaktor Sox2 dient er zur Pluripotenz und Erhaltung embryonaler Stammzellen (Chew et al. 2005). Interessanterweise zeigen auch primordiale Keimzellen in frühen Gestationswochen eine Expression von Oct-3/4, wobei diese im weiteren Verlauf der Keimzell-Differenzierung verloren geht. Neben der Pluripotenz und Differenzierung scheint Oct-3/4 auch bei der Apoptoseregulation eine wesentliche Rolle zu spielen, da ein Verlust von Oct-3/4 mit einer Induktion der Apoptose einhergeht (de Jong et al. 2008; Kehler et al. 2004; Pesce et al. 1998).

In dieser Arbeit präsentierten IGCNU, Seminome und embryonale Karzinome eine Expression von Oct-3/4, Seminome und IGCNU zu annähernd 100\%, embryonale Karzinome in 85,3\% der Fälle. 2 der 91 Teratome zeigten ebenfalls eine fokale Oct- 
3/4-Expression. Normales Hodengewebe, Dottersacktumoren und Chorionkarzinome zeigten keine Expression von Oct-3/4.

Santagata et al. (2007) beschrieben ebenfalls eine Expression von OCT-3/4 in allen untersuchten embryonalen Karzinomen $(n=18)$ und Seminomen $(n=20)$. Ähnliches beschrieben Gopalan et al. (2009), die in allen untersuchten IGCNU $(n=35)$, Seminomen $(n=8)$ und embryonalen Karzinomen $(n=50)$ Oct-3/4 nachweisen konnten. Im Vergleich zu diesen Studien ist auffällig, dass in der vorliegenden Arbeit nur 145 der 170 untersuchten embryonalen Karzinome eine Oct-3/4-Expression zeigten und somit keine Spezifität von 100\% gegeben ist. Dies steht in Gegensatz zu den Ergebnissen von Looijenga et al. in der ersten Studie, die die Oct-3/4-Expression in TGCT im Jahr 2003 untersuchte. Damals zeigten IGCNU, Seminome und embryonale Karzinome ein durchweg positives Ergebnis, was de Jong et al. 2005 nochmals reproduzierten (de Jong et al. 2005; Looijenga et al. 2003). Keiner der Autoren beschrieb eine Expression von Oct-3/4 in Teratomen, Dottersacktumoren und Chorionkarzinomen (Gopalan et al. 2009; Santagata et al. 2007). Nach weiterer Differenzierung zu den anderen nicht-seminomatösen Tumoren ist Oct-3/4 nicht mehr nachweisbar. Dies spricht für die Theorie einer Differenzierung von Dottersacktumoren, Teratomen und Chorionkarzinomen aus embryonalen Karzinomen.

Sox2 gehört zur Familie der Sox-Proteine, in der mindestens 20 verschiedene Proteine bekannt sind. Sox2 ist ein Transkriptionsfaktor in embryonalen Stammzellen, der viele seiner Funktionen in Zusammenarbeit mit Oct-3/4 ausübt (Chew et al. 2005). Als Komplex mit Oct-3/4 wird die Pluripotenz von Stammzellen erhalten. Zusätzlich ist Sox2 in neuronalen Stammzellen zu finden, wo es eine Rolle in der Entwicklung des Nervensystems spielt (Episkopou 2005). Veränderungen in Form einer Verminderung dieses Komplexes führen zur Differenzierung von Stammzellen (Chew et al. 2005).

Die Ergebnisse dieser Dissertation zeigten eine Expression für Sox2 in annähernd 100\% der embryonalen Karzinome und 29,7\% der Teratome, beschränkt auf den epithelialen Anteil. Alle anderen Entitäten, inklusive normalem Hodengewebe und IGCNU, zeigten keine Sox2-Expression. Zusätzlich zeigten Sertoli-Zellen eine positive Reaktion. 
Übereinstimmend gestaltete sich die positive Expression von Sox2 in embryonalen Karzinomen mit vorangegangenen Studien unabhängig von der Größe des Patientenkollektivs (de Jong et al. 2008; Gopalan et al. 2009; Santagata et al. 2007). Ebenfalls beschrieb keiner der Autoren eine Expression von Sox2 in den anderen Entitäten inklusive IGCNU, als Ausnahme ist lediglich das Teratom zu nennen. Teratome präsentierten ein heterogenes Bild. Als positiv für Sox2 wurde häufig der epitheliale Anteil der Tumoren beschrieben, wie auch de Jong et al. positive epitheliale Zellen in Teratomen nachweisen konnten. Santagata et al. werteten 17 von 19 Teratome positiv, wiesen aber daraufhin, dass sich die Anfärbbarkeit auf das Epithel beschränkte. Gopalan et al. hingegen beschrieben den neuroektodermalen Anteil in 11 von 14 Fällen unreifer Teratome als positiv und führten dies auf die Expression von Sox2 in neuronalen Stammzellen zurück. De Jong et al. konnten positive Zellen in Tubuli seminiferi, die IGCNU-Zellen enthalten, nachweisen und identifizierten diese als Sertoli-Zellen. Zusammenfassend ist zu postulieren, dass Sox2 hinsichtlich embryonaler Karzinome eine diagnostische Bedeutung hat.

CD 117 ist eine membranöse Rezeptor-Tyrosin-Kinase, die durch Bindung ihres Liganden Stem Cell Factor (SCF) ihre Funktion in der Proliferation, Differenzierung und dem Überleben von Stammzellen entwickelt (Runyan et al. 2006). Erstmals beschrieben wurde CD 117 in TGCT von Strohmeyer et al. im Jahr 1991 durch Untersuchungen auf DNA-und RNA-Ebene (Strohmeyer et al. 1991). CD 117 ist speziell auf hämatopoetischen Stammzellen, aber auch anderen Zelltypen, zu finden. Gonozyten im Hoden von Föten exprimieren CD 117, nach der 25. SSW ist diese Expression vermindert (Biermann et al. 2007a). Pathologisch nachgewiesen wurde CD 117 unter anderem in gastrointestinalen Stromatumoren und metastatischen Melanomen (Yu et al. 2007).

Ergebnisse dieser Arbeit präsentierten eine Expression von CD 117 in IGCNU (366 von 369) und Seminomen (331 von 350) in annähernd 100\% der Fälle, sowie einzelne positive Fälle in embryonalen Karzinomen (4 von 170) und Teratomen (10 von 91). Weder Dottersacktumoren noch Chorionkarzinome zeigten eine Expression und lediglich 1 Fall von untersuchten 286 normalen Hodengeweben zeigte sich positiv.

Die Expression von CD 117 in IGCNU und Seminomen bestätigte in der Literatur vorbeschriebene Untersuchungen, auch wenn diese auf kleiner Patientenkollektive 
bezogen waren (Gopalan et al. 2009; Lau et al. 2007; Leroy et al. 2002). Interessanterweise zeigten in dieser Dissertation 10 von 91 Teratomen eine Expression von CD 117, was in keiner Studie vorbeschrieben ist. Gopalan et al. beschrieben für 40 Teratome nur negative Ergebnisse und auch Lau et al. konnten in 13 Teratomen keine Expression von CD 117 feststellen. Allerdings beschrieben Gopalan et al. in 14 von 40 Dottersacktumoren eine Expression von CD 117, was sich in dieser Arbeit nicht reproduzieren ließ. Lau et al. untersuchten zwar auch Dottersacktumoren, aber die Arbeitsgruppe bezog sich nur auf 3 Fälle, daher ist dem Ergebnis dieser Arbeitsgruppe nur eingeschränkte Aussagekraft zuzuschreiben. Die geringe Anzahl an positiven embryonalen Karzinomen dieser Dissertation (4/170) deckt sich mit Ergebnissen der Studie von Gopalan et al., die ebenfalls in nur 3 von 50 embryonalen Karzinomen eine Expression von CD 117 feststellen konnten. Auch Leroy et al. beschrieben in ihrer Studie zur Unterscheidung von embryonalen Karzinomen und Seminomen in einem von 14 Fällen ein positives Ergebnis.

D2-40 ist ein monoklonaler Antikörper, der mit einem onkofetalen Antigen (M2A, Podoplanin) reagiert (Marks et al. 1999). Kaiserling beschrieb 2004 D2-40 als Marker für Lymphgefäßendothelien (Kaiserling 2004). Physiologisch ist das Antigen in fötalen Keimzellen bzw. Gonozyten des Hodens nachweisbar, des Weiteren scheint es in der Entwicklung von Sertoli-Zellen eine Rolle zu spielen (Baumal et al. 1989). Podoplanin wird möglicherweise eine Rolle in der interzellulären Adhäsion von Zellen zugedacht (Sonne et al. 2006). Einige maligne Tumoren wie Ovarialkarzinome, Osteosarkome und Blasenkarzinome exprimieren das zugehörige Antigen M2A (Marks et al. 1999).

In dieser Arbeit präsentierten IGCNU und Seminome eine Expression von D2-40 in $100 \%$ der Fälle, während nur sehr vereinzelte embryonale Karzinome (11 von 170) sowie Teratome (3 von 91) eine CD-117-Expression zeigten. Normales Hodengewebe, Dottersacktumoren und Chorionkarzinome waren in allen Fällen negativ.

Alle Studien stimmten darin überein, dass IGCNU und Seminome eine Anfärbbarkeit für D2-40 zeigten, während Chorionkarzinome in keiner Studie ein positives Ergebnis aufweisen konnten (Lau et al. 2007; Marks et al. 1999; Yu et al. 2007). Im Gegensatz zu Ergebnissen dieser Dissertation, beschrieben Marks et al. sowie Yu et al. eine vereinzelte Expression des zugehörigen Antigens in Dottersacktumoren. Beide 
Arbeitsgruppen bezogen sich allerdings nur auf Mischtumoren in einem sehr kleinen Patientenkollektiv (1/4 Fällen, 5/9 Fällen). Die Ergebnisse für embryonale Karzinome sind divergenter. Yu et al. beschrieben alle 19 untersuchten embryonale Karzinome als positiv, Marks et al. hingegen 50\% der 26 Fälle und Lau et al. nur 4 von 14 Fällen. Ähnlich verhält es sich mit dem Teratom, dessen Expressionsprofil ebenfalls in den verschiedenen Studien variiert und zwischen 0 und $50 \%$ positiver Fälle bei einem Patientenkollektiv von 13 bis 17 Fällen schwankt. Demzufolge ist eine Einordnung der Expression von D2-40 in diesen beiden Entitäten bislang schwer zu definieren.

Das CD-9-Gen ist auf Chromosom 12 lokalisiert und kodiert für ein Membranprotein, das in die Entwicklung sowie Motilität und Wachstum vieler Zellen (Knochenmark, Gehirn, Muskeln etc.) involviert ist. Außerdem scheint es in der Verschmelzung von Spermium und Eizelle eine Rolle zu spielen (Kanatsu-Shinohara et al. 2004). CD 9 wurde bisher von allen in dieser Arbeit verwendeten Markern am wenigsten in Verbindung mit TGCT untersucht. Es gibt nur eine Studie von der Arbeitsgruppe Biermann et al. aus dem Jahr 2007, die bisher Ergebnisse zu immunhistochemischen Untersuchungen von CD 9 in TGCT veröffentlichte. (Biermann et al. 2007b). Physiologisch haben Biermann et al. CD 9 in fötalen Gonozyten, aber nicht mehr in differenzierten fötalen Keimzellen, den PräSpermatogonien, nachgewiesen und daraus die Hypothese formuliert, dass zwischen Gonozyten und IGCNU eine Verbindung bestehen könnte. Andere Arbeitsgruppen beschäftigten sich mit CD 9 in verschiedensten Tumoren, so wies beispielsweise Kawashima et al. CD 9 in Tumoren des Gehirns nach, während Miyake et al. eine umgekehrte Korrelation zwischen dem Metatastasierungspotential von MammaKarzinomen und der CD-9-Expression fanden (Kawashima et al. 2002; Miyake et al. 1996). Higashiyama et al. konnten für Lungentumoren, die eine verminderte CD-9Expression aufwiesen, eine schlechtere Prognose feststellen (Higashiyama et al. 1995). Kanatsu-Shinohara et al. beschrieben die Expression von CD 9 in embryonalen, hämatopoetischen sowie neuronalen Stammzellen von Mäusen und entdeckten einen signifikanten Antieg von c-kit in CD-9-positiven Zellen (KanatsuShinohara et al. 2004). Einige Studien zusammenfassend formulierte Tanaka et al. 2009 die Hypothese, dass zwischen der CD-9-Expression und dem invasiven Wachstum von TGCT eine Verbindung bestehen könnte (Tanaka et al. 2009). 
Ergebnisse dieser Arbeit zeigten eine eindeutige Expression von CD 9 in IGCNU, Seminomen sowie embryonalen Karzinomen, eine überwiegende Expression in Teratomen $(83,5 \%)$ und eine positive Expression in 8 von 25 Chorionkarzinomen. Einzig Dottersacktumoren und normales Hodengewebe wiesen keine Expression von CD 9 auf.

Damit konnten die positiven Ergebnisse von Biermann et al. für IGCNU, Seminome und embryonale Karzinome reproduziert und für ein sehr viel größeres Kollektiv an Patienten bestätigt werden, da 2007 nur jeweils 10 Fälle untersucht wurden. Außerdem konnten neue Erkenntnisse über die Expression von CD 9 in den anderen nicht-seminomatösen Tumoren gewonnen werden. CD 9 ist von den hier untersuchten Markern für die Diagnostik von TGCT der einzige Antikörper neben Pan-CK, der eine große Anzahl an Teratomen anfärbte, dies könnte als Ansatzpunkt für weitere Untersuchungen dienen. Ebenso lässt die Anzahl an positiven Chorionkarzinomen Raum für weitere Untersuchungen. Lediglich Dottersacktumoren scheinen von allen untersuchten TGCT keinerlei Expression von CD 9 aufzuweisen.

Eine abschließende Übersicht der positiven Ergebnisse der immunhistochemischen Untersuchungen in dieser Dissertation findet sich in Tabelle 22. Für die Diagnostik und Erforschung der testikulären Keimzelltumoren werden auch in Zukunft die bereits bekannten, aber auch weitere neue immunhistochemische Marker Anwendung finden. 
Tabelle 22: Zusammenfassung der immunhistochemischen Ergebnisse (n=Fälle)

Anzahl der positiven Fälle (\%)

\begin{tabular}{|c|c|c|c|c|c|c|c|c|c|c|}
\hline Entität & Pan-CK & PLAP & CD 30 & AFP & ß-HCG & Oct-3/4 & Sox2 & CD 117 & D2-40 & CD 9 \\
\hline $\begin{array}{c}\text { normales } \\
\text { Hodengewebe } \\
(n=286)\end{array}$ & $4(1,4 \%)$ & $0(0 \%)$ & $0(0 \%)$ & $0(0 \%)$ & $0(0 \%)$ & $0(0 \%)$ & $0(0 \%)$ & $1(0,3 \%)$ & $0(0 \%)$ & $0(0 \%)$ \\
\hline IGCNU (n=369) & $333(90,2 \%)$ & $369(100 \%)$ & $0(0 \%)$ & $0(0 \%)$ & $0(0 \%)$ & $359(97.3 \%)$ & $0(0 \%)$ & $366(99,2 \%)$ & $369(100 \%)$ & $369(100 \%)$ \\
\hline Seminom $(n=350)$ & $21(6 \%)$ & $338(96,5 \%)$ & $3(0,9 \%)$ & $0(0 \%)$ & $0(0 \%)$ & $338(96,6 \%)$ & $0(0 \%)$ & $331(94,6 \%)$ & $350(100 \%)$ & $350(100 \%)$ \\
\hline Nicht-Seminom & & & & & & & & & & \\
\hline $\begin{array}{c}\text { Embryonales } \\
\text { Karzinom } \\
(n=170)\end{array}$ & $158(92,9 \%)$ & $96(56,5 \%)$ & $160(94,1 \%)$ & $4(2,4 \%)$ & $0(0 \%)$ & $145(85,3 \%)$ & $168(98,8 \%)$ & $4(2,4 \%)$ & $11(6,5 \%)$ & $170(100 \%)$ \\
\hline $\begin{array}{c}\text { Teratom } \\
(n=91)\end{array}$ & $54(59,3 \%)$ & $6(6,5 \%)$ & $0(0 \%)$ & $11(12 \%)$ & $0(0 \%)$ & $2(2,2 \%)$ & $27(29,7 \%)$ & $10(11 \%)$ & $3(3,4 \%)$ & $76(83,5 \%)$ \\
\hline $\begin{array}{l}\text { Dottersacktumor } \\
\qquad(n=23)\end{array}$ & $23(100 \%)$ & $0(0 \%)$ & $0(0 \%)$ & $23(100 \%)$ & $0(0 \%)$ & $0(0 \%)$ & $0(0 \%)$ & $0(0 \%)$ & $0(0 \%)$ & $0(0 \%)$ \\
\hline $\begin{array}{l}\text { Chorionkarzinom } \\
\qquad(n=25)\end{array}$ & $25(100 \%)$ & $0(0 \%)$ & $0(0 \%)$ & $0(0 \%)$ & $23(92 \%)$ & $0(0 \%)$ & $0(0 \%)$ & $0(0 \%)$ & $0(0 \%)$ & $8(32 \%)$ \\
\hline
\end{tabular}




\subsection{Tissue-Microarray-Technik}

Die in der vorliegenden Dissertation angewandten Tissue-Microarrays sind besonders für die Analyse einer großen Anzahl an Gewebeproben prädestiniert. Der aufwendigste und zeitintensivste Arbeitsschritt bei der Herstellung der TMAs ist das Zusammenstellen des Patientenkollektivs (Heraussuchen der archivierten Schnittpräparate, Markierung der Tumorareale auf den Schnittpräparaten, Zusammenstellung der zugehörigen Paraffin-Gewebeblöcke). Die Herstellung eines TMAs nimmt dagegen relativ wenig Zeit in Anspruch und erwies sich als unkompliziert. Das Entnehmen von Stanzzylindern aus den Donorblöcken gelang meist problemlos, lediglich Blöcke von Tumoren, die schon mehrfach untersucht worden waren, variierten in der Dicke ihres Materials. Demzufolge war es in einigen wenigen Fällen nicht möglich, mit der Apparatur des Tissue-Microarrayer Stanzzylinder zu entnehmen bzw. die entnommenen Stanzen waren unterschiedlich lang und beim Schneiden der Praffinblöcke traten Schwierigkeiten auf. Die verschiedenen Gewebebeschaffenheiten der einzelnen Tumorentitäten verursachten bei der Entnahme der Stanzzylinder keine Probleme. Als teilweise problematisch entwickelte sich bei der Auswertung die Zerstörung bzw. das Verschwinden einzelner Stanzzylinder. Ursache hierfür war einerseits die zu geringe Länge der Stanzen durch wiederholtes Schneiden des Donorblockes und andererseits die einzelnen Arbeitsschritte der Immunhistochemie. In einigen Fällen war eine Auswertung der Stanze trotzdem möglich, da nur ein Teil dieser fehlerhaft war, aber noch genügend auswertbares Material vorhanden war. Gelang eine repräsentative Auswertung derartiger Stanzen nicht, wurde der Fall aussortiert und nicht in die Auswertung aufgenommen. Dieses Problem stellt einen zu diskutierenden Nachteil der TMATechnik dar (Hoos and Cordon-Cardo 2001). Skacel et al. beschrieben 2002, dass abhängig von dem gewählten Durchmesser der Stanzzylinder zwischen 90-100\% der Stanzen auswertbar waren. Je größer der gewählte Durchmesser war, desto höher war die Anzahl des auswertbaren Materials (Skacel et al. 2002). Der in dieser Dissertation verwendete Stanzzylinder hatte einen Durchmesser von $1 \mathrm{~mm}$ und lag damit über dem mehrheitlich angewandten Durchmesser von 0,6 mm (Voduc et al. 2008). Um die Repräsentation eines Tumors in seiner Heterogenität zu gewährleisten, wird das Übertragen mehrerer Stanzzylinder pro zu untersuchenden Fall empfohlen, wobei in der Regel wie in der vorliegenden Arbeit 3 Stanzzylinder 
ausreichend erscheinen (Camp et al. 2000; Parker et al. 2002). Darüberhinaus ist bei einem derartigen Vorgehen gewährleistet, dass durch Untersuchungstechniken bedingtes Fehlen eines Stanzzylinders der Patientenfall aus dem Kollektiv genommen werden muss (Skacel et al. 2002).

Zusammenfassend ist festzustellen, dass durch die technisch einfache und gut etablierte TMA-Technik ein großes Patientenkollektiv auf wenigen Objektträgern untersucht werden kann und die Durchführung von immunhistochemischen Untersuchungen bei geringerem Materialverbrauch deutlich erleichtert wird. 


\section{$5 \quad$ Zusammenfassung}

Maligne Keimzelltumoren des Hodens sind die häufigsten soliden malignen Tumoren des jungen Mannes, die in den letzten 50 Jahren einen kontinuierlichen Anstieg der Inzidenz zeigen und somit eine klinisch relevante Tumorgruppe repräsentieren. Aufgrund ihres biologischen, klinischen und therapeutischen Verhaltens werden die malignen Keimzelltumoren des Hodens in die zwei großen Gruppen der Seminome und Nicht-Seminome eingeteilt. Entsprechend ihrer Differenzierung werden die NichtSeminome histopathologisch weiter in embryonale Karzinome, Dottersacktumoren, Chorionkarzinome und Teratome unterschieden. Häufig treten maligne Keimzelltumoren des Hodens auch als Mischtumoren auf, die sowohl seminomatöse als auch nicht-seminomatöse Tumoranteile tragen. Für eine Tumor-spezifische Therapie in Form einer Chemo- und/oder Radiotherapie ist die exakte histopathologische Diagnose eines malignen Keimzelltumors des Hodens unerlässlich. In der vorliegenden Arbeit wurden bekannte als auch neue immunhistochemische Marker für die pathologische Diagnostik maligner Keimzelltumoren des Hodens mittels Tissue-Microarray-Technik bei 204 männlichen Patienten untersucht und ein immunhistochemischer Algorithmus entwickelt. Es konnte gezeigt werden, dass Antikörper gegen PLAP, Oct-3/4, D2-40, CD 117 und CD 9 für die Diagnostik der intratubulären Keimzellneoplasie und Seminome die höchste Sensitivität aufweisen. Im Gegensatz dazu ließen sich embryonale Karzinome mit Antikörpern gegen Pan-CK, Sox2, CD 9 und CD 30 sowie Teratome mit Antikörpern gegen Pan-CK (epitheliale Anteile) oder CD 9 am sensitivsten nachweisen. Für Dottersacktumoren bzw. Chorionkarzinome hatten die lange bekannten Antikörper gegen Pan-CK und AFP bzw. ß-HCG die höchste Sensitivität. Normale Keimzellen der Hodentubuli zeigten für alle angewandten Antikörper keine Expression. Anhand der erhobenen Expressionsprofile der unterschiedlichen malignen Keimzelltumoren des Hodens konnte ein immunhistochemischer Algorithmus für die Diagnostik maligner Keimzelltumoren des Hodens entwickelt werden (Abb. 15). Zusammenfassend sollte in der Diagnostik maligner Keimzelltumoren des Hodens immer ein Antikörper-Panel zur exakten und therapierelevanten histopathologischen Diagnose unter Einbezug des entwickelten immunhistochemischen Algorithmus zur Anwendung kommen. 
Abbildung 15: Immunhistochemischer Algorithmus zur Diagnostik maligner Keimzelltumoren des Hodens

\title{
Normales Hodengewebe
}

Antikörper-Panel negativ

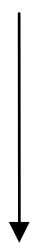

\section{IGCNU}

\author{
Pan-CK + \\ PLAP + \\ Oct-3/4+ \\ CD $117+$ \\ D2-40 + \\ CD $9+$
}
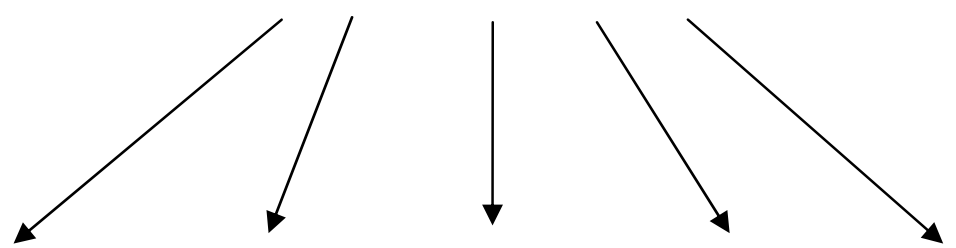

\section{SE}

EC

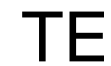

DST

CC

$\begin{array}{ccccc}\text { PLAP }+ & \text { Pan-CK }+ & \text { Pan-CK }+ & \text { Pan-CK }+ & \text { Pan-CK + } \\ \text { Oct-3/4 }+ & \text { CD } 30+ & \text { CD } 9+ & \text { AFP }+ & \text { B-HCG }+ \\ \text { CD } 117+ & \text { Oct-3/4 } & & & \\ \text { D2-40 + } & \text { Sox } 2+ & & & \\ \text { CD } 9+ & \text { CD } 9+ & & & \end{array}$




\section{$6 \quad$ Literaturverzeichnis}

Battifora $\mathrm{H}$ (1986): The multitumor (sausage) tissue block: novel method for immunohistochemical antibody testing. Lab Invest $\underline{55}$, 244-248.

Battifora H, Sheibani K, Tubbs RR, Kopinski MI, Sun TT (1984): Antikeratin antibodies in tumor diagnosis. Distinction between seminoma and embryonal carcinoma. Cancer 54, 843-848.

Baumal R, Bailey D, Giwercman A, Skakkebaek N, Stratis M, Marks A (1989): A novel maturation marker for human Sertoli cells. Int J Androl 12, 354-359.

Beckstead JH (1983): Alkaline phosphatase histochemistry in human germ cell neoplasms. Am J Surg Pathol ㄱ, 341-349.

Beilby JO, Horne CH, Milne GD, Parkinson C (1979): Alpha-fetoprotein, alpha-1antitrypsin, and transferrin in gonadal yolk-sac tumours. J Clin Pathol $\underline{32}$, 455-461.

Biermann K, Göke F, Nettersheim D, Eckert D, Zhou H, Kahl P, Gashaw I, Schorle H, Büttner R (2007a): c-KIT is frequently mutated in bilateral germ cell tumours and down-regulated during progression from intratubular germ cell neoplasia to seminoma. J Pathol 213, 311-318.

Biermann K, Heukamp LC, Steger K, Zhou H, Franke FE, Guetgemann I, Sonnack V, Brehm R, Berg J, Bastian PJ (2007b): Gene expression profiling identifies new biological markers of neoplastic germ cells. Anticancer Res 27, 3091-3100.

Böcker W, Denk H, Heitz PU, Moch H (Hg.): Hodentumoren; in: Lehrbuch Pathologie, Urban \& Fischer in Elsevier, München 2008, 908-915.

Bokemeyer C, Harstrick A, Schöffski P, Schmoll HJ, Poliwoda H (1992): [Germ-cell tumors of the testis. The epidemiological and etiological aspects]. Dtsch Med Wochenschr 117, 1532-1537.

Burke AP, Mostofi FK (1988): Placental alkaline phosphatase immunohistochemistry of intratubular malignant germ cells and associated testicular germ cell tumors. Hum Pathol $\underline{19}$, 663-670.

Camp RL, Charette LA, Rimm DL (2000): Validation of tissue microarray technology

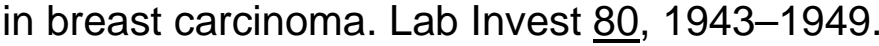

Cheville JC, Rao S, Iczkowski KA, Lohse CM, Pankratz VS (2000): Cytokeratin expression in seminoma of the human testis. Am J Clin Pathol 113, 583-588.

Chew J, Loh Y, Zhang W, Chen X, Tam W, Yeap L, Li P, Ang Y, Lim B, Robson P (2005): Reciprocal transcriptional regulation of Pou5f1 and Sox2 via the Oct4/Sox2 complex in embryonic stem cells. Mol Cell Biol 25, 6031-6046.

Cools M, Drop SLS, Wolffenbuttel KP, Oosterhuis JW, Looijenga LHJ (2006): Germ cell tumors in the intersex gonad: old paths, new directions, moving frontiers. Endocr Rev 27, 468-484

De Jong J, Stoop $\mathrm{H}$, Dohle GR, Bangma $\mathrm{CH}$, Kliffen M, van Esser JWJ, van den Bent M, Kros JM, Oosterhuis JW, Looijenga LHJ (2005): Diagnostic value of OCT3/4 for pre-invasive and invasive testicular germ cell tumours. J Pathol $\underline{206}, 242-249$. 
De Jong J, Stoop H, Gillis AJM, van Gurp RJHLM, van de Geijn GM, de Boer M, Hersmus R, Saunders PTK, Anderson RA, Oosterhuis JW (2008): Differential expression of SOX17 and SOX2 in germ cells and stem cells has biological and clinical implications. J Pathol 215, 21-30.

De Matteis A, di Silverio F (1987): Immunological tissue markers in the diagnosis of testicular cancer. World J Urol $\underline{5}, 138-142$.

Dieckmann K, Pichlmeier U (2004): Clinical epidemiology of testicular germ cell tumors. World J Urol 22, 2-14

Eble JN (1994): Spermatocytic seminoma. Hum Pathol 25, 1035-1042.

Eble JL, Sauter G, Epstein JI, Sesterhenn IA (Hg.) : Tumours of the Testis and the Paratesticular Tissue; in: Pathology and Genetics of Tumours of the Urinary System and Male Genital Organs. Who Classification of Tumours Volume 7, International Agency for Research on Cancer, Genf 2004, 217-248.

Eglen DE, Ulbright TM (1987): The differential diagnosis of yolk sac tumor and seminoma. Usefulness of cytokeratin, alpha-fetoprotein, and alpha-1-antitrypsin immunoperoxidase reactions. Am J Clin Pathol 88, 328-332.

Ekbom A, Akre O (1998): Increasing incidence of testicular cancer--birth cohort effects. APMIS $\underline{106}, 225-231$.

Emerson RE, Ulbright TM (2005): The use of immunohistochemistry in the differential diagnosis of tumors of the testis and paratestis. Sem Diagn Pathol 22, 33-50.

Episkopou V (2005): SOX2 functions in adult neural stem cells. Trends Neurosci $\underline{28}$, 219-221.

Fogel M, Lifschitz-Mercer B, Moll R, Kushnir I, Jacob N, Waldherr R, Livoff A, Franke WW, Czernobilsky B (1990): Heterogeneity of intermediate filament expression in human testicular seminomas. Differentiation $45,242-249$.

Göbel U, Schneider DT, Calaminus G, Haas RJ, Schmidt P, Harms D (2000): Germcell tumors in childhood and adolescence. GPOH MAKEI and the MAHO study groups. Ann Oncol 11, 263-271.

Gopalan A, Dhall D, Olgac S, Fine SW, Korkola JE, Houldsworth J, Chaganti RS, BosI GJ, Reuter VE, Tickoo SK (2009): Testicular mixed germ cell tumors: a morphological and immunohistochemical study using stem cell markers, OCT3/4, SOX2 and GDF3, with emphasis on morphologically difficult-to-classify areas. Mod Pathol 22, 1066-1074.

Higashiyama M, Taki T, leki Y, Adachi M, Huang CL, Koh T, Kodama K, Doi O, Miyake M (1995): Reduced motility related protein-1 (MRP-1/CD9) gene expression as a factor of poor prognosis in non-small cell lung cancer. Cancer Res $\underline{55}, 6040$ 6044.

Hittmair A, Rogatsch H, Hobisch A, Mikuz G, Feichtinger H (1996): CD30 expression in seminoma. Hum Pathol 27, 1166-1171.

Hoei-Hansen CE, Rajpert-De Meyts E, Daugaard G, Skakkebaek NE (2005):

Carcinoma in situ testis, the progenitor of testicular germ cell tumours: a clinical review. Ann Oncol 16, 863-868.

Hoei-Hansen CE, Holm M, Rajpert-De Meyts E, Skakkebaek NE (2003): Histological evidence of testicular dysgenesis in contralateral biopsies from 218 patients with testicular germ cell cancer. J Pathol 200, 370-374. 
Holzik MFL, Sijmons RH, Hoekstra-Weebers JE, Sleijfer DT, Hoekstra HJ (2008):

Clinical and genetic aspects of testicular germ cell tumours. Hered Cancer Clin Pract $\underline{6}, 3-14$.

Honecker F, Oosterhuis JW, Mayer F, Hartmann JT, Bokemeyer C, Looijenga LHJ (2004): New insights into the pathology and molecular biology of human germ cell tumors. World J Urol 22, 15-24.

Hoos A, Cordon-Cardo C (2001): Tissue microarray profiling of cancer specimens and cell lines: opportunities and limitations. Lab Invest 81, 1331-1338.

Jacobsen GK, Jacobsen M (1983): Alpha-fetoprotein (AFP) and human chorionic gonadotropin (HCG) in testicular germ cell tumours. A prospective immunohistochemical study. Acta Pathol Microbiol Immunol Scand A $\underline{91}$, 165-176.

Jawhar NMT (2009): Tissue Microarray: A rapidly evolving diagnostic and research tool. Ann Saudi Med 29, 123-127.

Kaiserling E (2004): Immunhistochemische Darstellung von Lymphgefäßen mit D240 in der diagnostischen Pathologie. Pathologe 25, 362-374.

Kanatsu-Shinohara M, Toyokuni S, Shinohara T (2004): CD9 is a surface marker on mouse and rat male germline stem cells. Biol Reprod $\underline{70}$, 70-75.

Kawashima M, Doh-ura K, Mekada E, Fukui M, Iwaki T (2002): CD9 expression in solid non-neuroepithelial tumors and infiltrative astrocytic tumors. J Histochem Cytochem 50, 1195-1203.

Kehler J, Tolkunova E, Koschorz B, Pesce M, Gentile L, Boiani M, Lomeli H, Nagy A, McLaughlin KJ, Schöler HR (2004): Oct4 is required for primordial germ cell survival. EMBO Rep $\underline{5}, 1078-1083$.

Kononen J, Bubendorf L, Kallioniemi A, Bärlund M, Schraml P, Leighton S, Torhorst J, Mihatsch MJ, Sauter G, Kalioniemi OP (1998): Tissue microarrays for highthroughput molecular profiling of tumor specimens. Nat Med $\underline{4}, 844-847$.

Krege S, Beyer J, Souchon R, Albers P, Albrecht W, Algaba F, Bamberg M, Bodrogi I, Bokemeyer C, Cavallin-Stahl E (2008a): European consensus conference on diagnosis and treatment of germ cell cancer: a report of the second meeting of the European Germ Cell Cancer Consensus group (EGCCCG): part I. Eur Urol 53, 478496.

Krege S, Beyer J, Souchon R, Albers P, Albrecht W, Algaba F, Bamberg M, Bodrogi I, Bokemeyer C, Cavallin-Stahl E (2008b): European consensus conference on diagnosis and treatment of germ cell cancer: a report of the second meeting of the European Germ Cell Cancer Consensus Group (EGCCCG): part II. Eur Urol $\underline{53}$, 497-513.

Kumar V, Abbas AK, Fausto N (Hg.): Germ Cell Tumors; in: Robbins and Cotran Pathologic Basis of Disease. Saunders Book Company/ Elsevier, Philadelphia 2009, 987-992.

Lau SK, Weiss LM, Chu PG (2007): D2-40 immunohistochemistry in the differential diagnosis of seminoma and embryonal carcinoma: a comparative immunohistochemical study with KIT (CD117) and CD30. Mod Pathol 20, 320-325.

Leroy X, Augusto D, Leteurtre E, Gosselin B (2002): CD30 and CD117 (c-kit) used in combination are useful for distinguishing embryonal carcinoma from seminoma. $\mathrm{J}$. Histochem. Cytochem 50, 283-285. 
Looijenga LHJ (2009): Human testicular (non)seminomatous germ cell tumours: the clinical implications of recent pathobiological insights. J Pathol 218, 146-162.

Looijenga LHJ, Oosterhuis JW (1999): Pathogenesis of testicular germ cell tumours. Rev Reprod 4 , 90-100.

Looijenga LHJ, Stoop H, Leeuw HPJC de, Gouveia Brazao CA de, Gillis AJM, van Roozendaal KEP, van Zoelen EJJ, Weber RFA, Wolffenbuttel KP, van Dekken H (2003): POU5F1 (OCT3/4) identifies cells with pluripotent potential in human germ cell tumors. Cancer Res $\underline{63}, 2244-2250$.

Marks A, Sutherland DR, Bailey D, Iglesias J, Law J, Lei M, Yeger H, Banerjee D, Baumal R (1999): Characterization and distribution of an oncofetal antigen (M2A antigen) expressed on testicular germ cell tumours. Br J Cancer $\underline{80}, 569-578$.

McKay DG, Hertig AT, Adams EC, Danziger S (1953): Histochemical observations on the germ cells of human embryos. Anat Rec $\underline{117}, 201-219$.

Miettinen M, Lehto VP, Virtanen I (1984): Antibodies to intermediate filament proteins in the diagnosis and classification of human tumors. Ultrastruct Pathol $\underline{7}, 83-107$.

Miettinen M, Virtanen I, Talerman A (1985): Intermediate filament proteins in human testis and testicular germ-cell tumors. Am J Pathol 120, 402-410.

Millán JL, Fishman WH (1995): Biology of human alkaline phosphatases with special reference to cancer. Crit Rev Clin Lab Sci 32, 1-39.

Miyake M, Nakano K, Itoi SI, Koh T, Taki T (1996): Motility-related protein-1 (MRP$1 / C D 9)$ reduction as a factor of poor prognosis in breast cancer. Cancer Res $\underline{56}$, 1244-1249.

Morinaga S, Ojima M, Sasano N (1983): Human chorionic gonadotropin and alphafetoprotein in testicular germ cell tumors. An immunohistochemical study in comparison with tissue concentrations. Cancer $\underline{52}, 1281-1289$.

Niehans GA, Manivel JC, Copland GT, Scheithauer BW, Wick MR (1988):

Immunohistochemistry of germ cell and trophoblastic neoplasms. Cancer $\underline{62}, 1113-$ 1123.

Oosterhuis JW, Kersemaekers AMF, Jacobsen GK, Timmer A, Steyerberg EW, Molier M, van Weeren PC, Stoop H, Looijenga LHJ (2003): Morphology of testicular parenchyma adjacent to germ cell tumours. An interim report. APMIS $\underline{111}, 32-42$.

Oosterhuis JW, Looijenga LHJ (2005): Testicular germ-cell tumours in a broader perspective. Nat Rev Cancer $\underline{5}, 210-222$.

Paiva J, Damjanov I, Lange PH, Harris H (1983): Immunohistochemical localization of placental-like alkaline phosphatase in testis and germ-cell tumors using monoclonal antibodies. Am J Pathol 111, 156-165.

Parker RL, Huntsman DG, Lesack DW, Cupples JB, Grant DR, Akbari M, Gilks CB (2002): Assessment of interlaboratory variation in the immunohistochemical determination of estrogen receptor status using a breast cancer tissue microarray. Am J Clin Pathol 117, 723-728.

Parkin DM, Bray F, Ferlay J, Pisani P (2001): Estimating the world cancer burden: Globocan 2000. Int J Cancer 94, 153-156. 
Pesce M, Wang X, Wolgemuth DJ, Schöler H (1998): Differential expression of the Oct-4 transcription factor during mouse germ cell differentiation. Mech Dev $\underline{71}$, 8998.

Rajpert-De Meyts E, Skakkebaek NE (1994): Expression of the c-kit protein product in carcinoma-in-situ and invasive testicular germ cell tumours. Int J Androl 17, 85-92.

Riede U, Werner M, Schaefer H: Keimzelltumoren; in: Allgemeine und spezielle Pathologie, Thieme, Stuttgart 2004, 920-925.

Runyan C, Schaible K, Molyneaux K, Wang Z, Levin L, Wylie C (2006): Steel factor controls midline cell death of primordial germ cells and is essential for their normal proliferation and migration. Development 133, 4861-4869.

Santagata S, Ligon KL, Hornick JL (2007): Embryonic stem cell transcription factor signatures in the diagnosis of primary and metastatic germ cell tumors. Am J Surg Pathol $\underline{31}$, 836-845.

Schefer H, Schöpfer A, Arnold W, Mattmann S, Thum P, Stucki PM (2003): Hodentumore. Schweiz Med Forum 40, 950-959.

Schwab U, Stein H, Gerdes J, Lemke H, Kirchner H, Schaadt M, Diehl V (1982): Production of a monoclonal antibody specific for Hodgkin and Sternberg-Reed cells of Hodgkin's disease and a subset of normal lymphoid cells. Nature 299, 65-67.

Skacel M, Skilton B, Pettay JD, Tubbs RR (2002): Tissue microarrays: a powerful tool for high-throughput analysis of clinical specimens: a review of the method with validation data. Appl. Immunohistochem. Mol Morphol 10, 1-6.

Skakkebaek NE (1972): Possible carcinoma-in-situ of the testis. Lancet 1972, II, 516-517.

Skakkebaek NE, Rajpert-De Meyts E, Main KM (2001): Testicular dysgenesis syndrome: an increasingly common developmental disorder with environmental aspects. Hum Reprod 16, 972-978.

Smith CA, Gruss HJ, Davis T, Anderson D, Farrah T, Baker E, Sutherland GR, Brannan Cl, Copeland NG, Jenkins NA (1993): CD30 antigen, a marker for Hodgkin's lymphoma, is a receptor whose ligand defines an emerging family of cytokines with homology to TNF. Cell $\underline{73}, 1349-1360$.

Sonne SB, Herlihy AS, Hoei-Hansen CE, Nielsen JE, Almstrup K, Skakkebaek NE, Marks A, Leffers H, Rajpert-De Meyts E (2006): Identity of M2A (D2-40) antigen and gp36 (Aggrus, T1A-2, podoplanin) in human developing testis, testicular carcinoma in situ and germ-cell tumours. Virchows Arch 449, 200-206.

Stone JM, Cruickshank DG, Sandeman TF, Matthews JP (1991): Laterality, maldescent, trauma and other clinical factors in the epidemiology of testis cancer in Victoria, Australia. Br J Cancer 64, 132-138.

Strohmeyer T, Peter S, Hartmann M, Munemitsu S, Ackermann R, Ullrich A, Slamon DJ (1991): Expression of the hst-1 and c-kit protooncogenes in human testicular germ cell tumors. Cancer Res $\underline{51}, 1811-1816$.

Talerman A (1980): Endodermal sinus (yolk sac) tumor elements in testicular germcell tumors in adults: comparison of prospective and retrospective studies. Cancer. $\underline{46}, 1213-1217$. 
Tanaka K, Okamoto S, Ishikawa Y, Tamura H, Hara T (2009): DDX1 is required for testicular tumorigenesis, partially through the transcriptional activation of $12 p$ stem cell genes. Oncogene 28, 2142-2151.

Ulbright TM (2005): Germ cell tumors of the gonads: a selective review emphasizing problems in differential diagnosis, newly appreciated, and controversial issues. Mod Pathol $\underline{18}, 61-79$.

Van Casteren NJ, Jong J de, Stoop H, Steyerberg EW, Bekker-Grob EW de, Dohle GR, Oosterhuis JW, Looijenga LHJ (2008): Evaluation of testicular biopsies for carcinoma in situ: immunohistochemistry is mandatory. Int J Androl 32, 666-674.

Vilar E, Calvo E, Tabernero J (2006): Molecular biology of testicular germ cell tumors. Clin Transl Oncol $\underline{8}$, 846-850.

Voduc D, Kenney C, Nielsen TO (2008): Tissue microarrays in clinical oncology. Semin Radiat Oncol 18, 89-97.

Weissbach L, Bussar-Maatz R, Löhrs U, Schubert GE, Mann K, Hartmann M, Dieckmann KP, Fassbinder J (1999): Prognostic factors in seminomas with special respect to HCG: results of a prospective multicenter study. Seminoma Study Group. Eur Urol 36, 601-608.

Wick MR, Swanson PE, Manivel JC (1987): Placental-like alkaline phosphatase reactivity in human tumors: an immunohistochemical study of 520 cases. Hum Pathol $\underline{18}, 946-954$.

Yu H, Pinkus GS, Hornick JL (2007): Diffuse membranous immunoreactivity for podoplanin (D2-40) distinguishes primary and metastatic seminomas from other germ cell tumors and metastatic neoplasms. Am J Clin Pathol 128, 767-775. 


\section{Abbildungsverzeichnis}

Abbildung 1: Manueller Tissue Arrayer mit TMA Booster Key und Halteapparat für den Leerblock .... 12 Abbildung 2: Stanzvorrichtung des manuellen Tissue-Arrayers mit Halteapparatur für den Leerblock 13 Abbildung 3: Beispiel eines TMAs und des korrespondierenden HE-Schnittes. 14

Abbildung 4: Altersverteilung des untersuchten Patientenkollektivs .............................................. 18

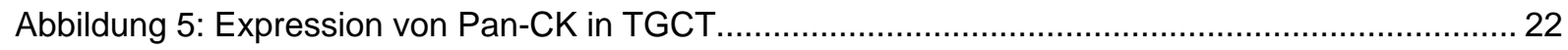

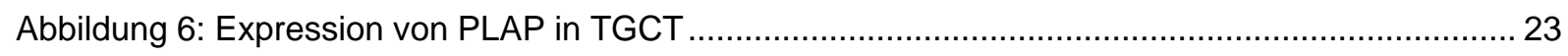

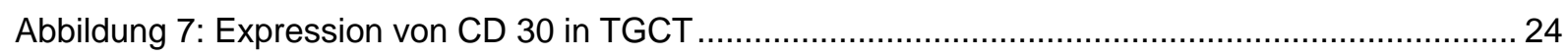

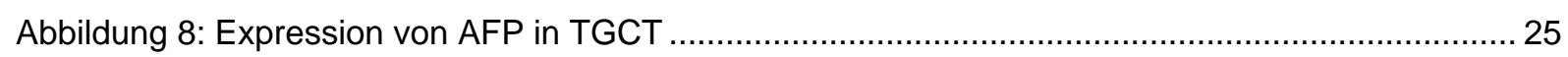

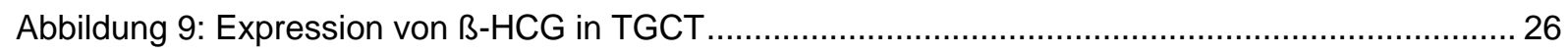

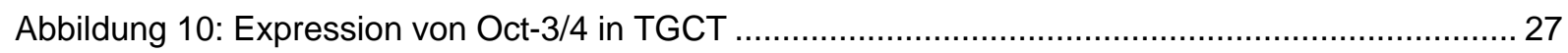

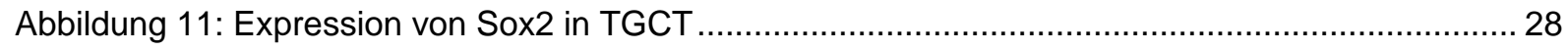

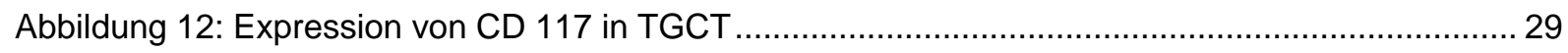

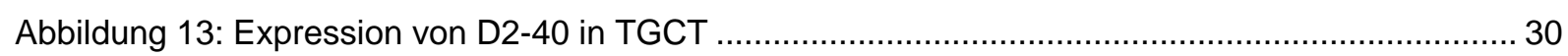

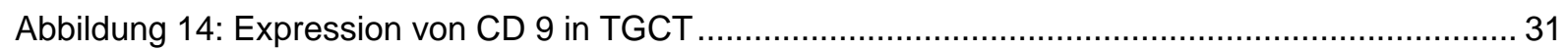

Abbildung 15: Immunhistochemischer Algorithmus zur Diagnostik maligner Keimzelltumoren des

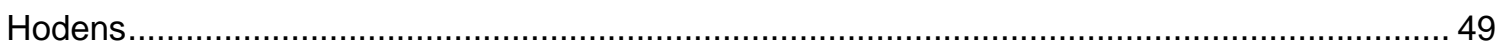




\section{Tabellenverzeichnis}

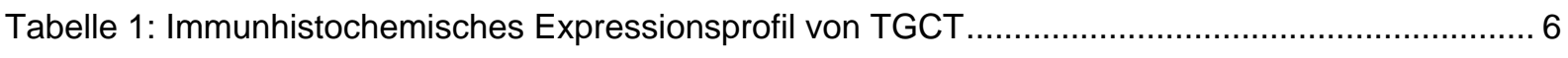

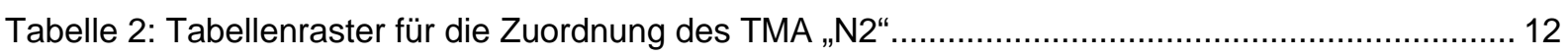

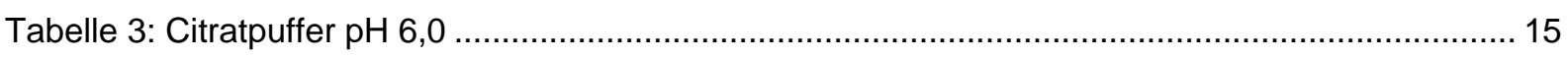

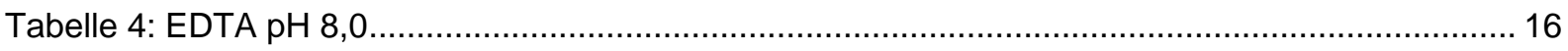

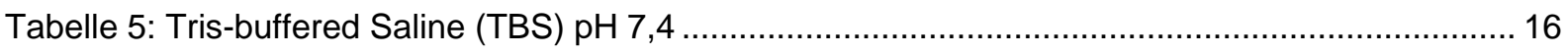

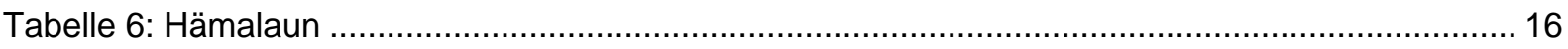

Tabelle 7: Antikörperverdünnung, Antigendemaskierung und Färbemethode.................................... 16

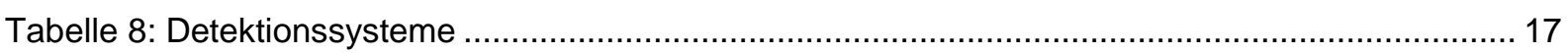

Tabelle 9: Tumorstadienverteilung des untersuchten Patientenkollektivs ........................................ 19

Tabelle 10: Anatomische Lokalisation der malignen Keimzelltumoren des Hodens............................. 19

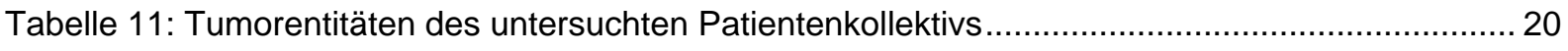

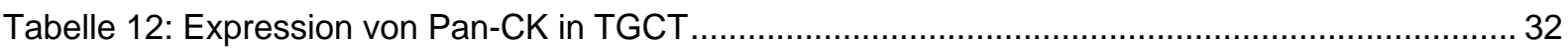

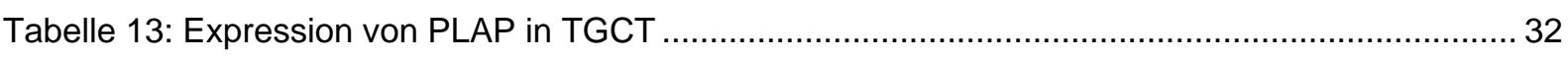

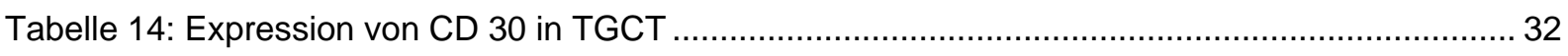

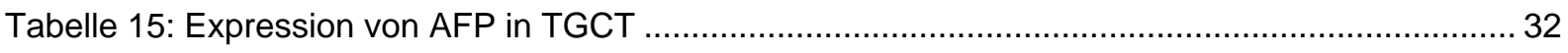

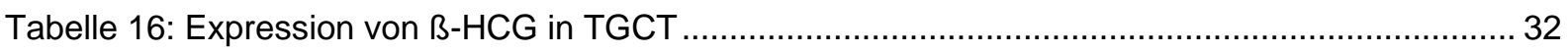

Tabelle 17: Expression von Oct-3/4 in TGCT

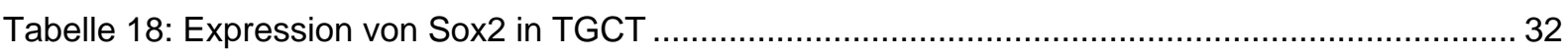

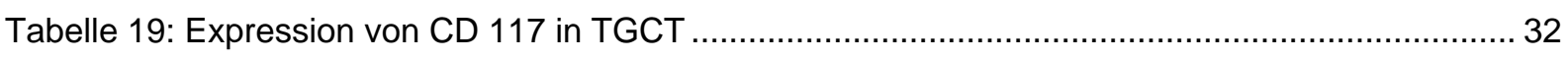

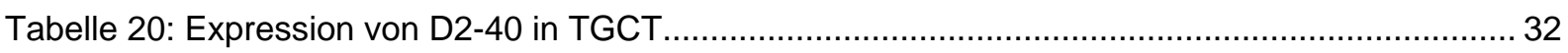

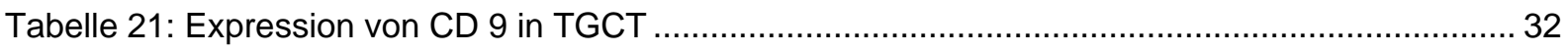

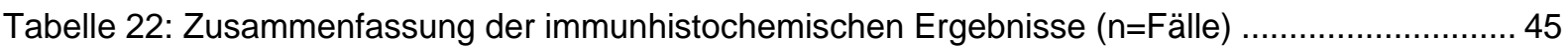




\section{Danksagung:}

Mein besonderer Dank gilt PD Dr. Stefan Schweyer, der mir dieses Thema überlassen hat und allzeit bereit war, mir mit Hilfe zur Seite zu stehen. Eine bessere Betreuung kann man sich nicht wünschen!

Professor Radzun möchte ich für die Überlassung des Arbeitsplatzes und die Bereitstellung aller nötigen Materialien danken.

Aus dem Labor möchte ich mich besonders bei Anke Klages und Melanie Gebhardt bedanken, die mir bei all meinen untersuchungstechnischen Problemen immer mit Rat und Tat geholfen haben.

Außerdem möchte ich mich bei Felix Bremmer bedanken, durch den der Kontakt zu Stefan Schweyer und damit diese Doktorarbeit entstand und der mir beim Schreiben dieser Dissertation in manchen Verzweiflungsmomenten immer wieder neue Tipps und Anregungen gab! 


\section{Lebenslauf:}

Ich wurde am 5. Januar 1981 in Tübingen geboren. Durch einen beruflich bedingten Umzug meiner Eltern nach Kiel besuchte ich dort von 1987 bis 1991 die ReventlouGrundschule. Hiernach wechselte ich auf das Gymnasium, in die Kieler Gelehrtenschule. 1997 erfolgte mein Umzug nach Stuttgart, wo ich bis zum Abitur im Jahr 2000 das Hölderlin-Gymnasium besuchte. Nach dem Abitur absolvierte ich im Sommer 2000 ein 2-monatiges Pflegepraktikum im Diakonissenkrankenhaus in Stuttgart. Während ich auf einen Studienplatz für Medizin wartete, arbeitete ich im Aufgabenfeld einer Arzthelferin von Oktober 2000 bis Januar 2003 in der gynäkologischen und geburtshilflichen Praxis mit dem Schwerpunkt Kinderwunschtherapie meines Vaters in Stuttgart. Im April 2003 begann ich mein Studium der Humanmedizin an der Georg-August-Universität in Göttingen, wo ich im Sommer 2005 erfolgreich das Physikum/1. Staatsexamen bestand. 2007 begann ich mit dem praktischen Teil dieser Dissertation bei PD Dr. Schweyer in der Abteilung Pathologie der Universitätsmedizin Göttingen. Im Herbst 2009 beendete ich mein Studium erfolgreich mit Ablegen des 2. Staatsexamens. Bis zum Frühjahr 2010 arbeitete ich an der Fertigstellung dieser Dissertation. Im Sommer 2010 begann ich meine Tätigkeit als Assistenzärztin in der Abteilung für Gynäkologie und Geburtshilfe im Johannes Wesling Klinikum in Minden. 